\title{
IL-1及-PRE-CONDITIONED MESENCHYMAL STEM/STROMAL CELLS' SECRETOME MODULATES THE INFLAMMATORY RESPONSE AND AGGRECAN DEPOSITION IN THE INTERVERTEBRAL DISC
}

\author{
J.R. Ferreira ${ }^{1,2,3}$, G.Q. Teixeira ${ }^{1,2,3, \#}$, E. Neto ${ }^{1,2}$, C. Ribeiro-Machado ${ }^{1,2}$, A.M. Silva ${ }^{1,2,3}$, J. Caldeira ${ }^{1,2}$,
} C. Leite Pereira ${ }^{1,2}$, S. Bidarra ${ }^{1,2}$, A.F. Maia ${ }^{1,4}$, M. Lamghari ${ }^{1,2,3}$, M.A. Barbosa ${ }^{1,2,3}$ and R.M. Gonçalves ${ }^{1,2,3, *}$

${ }^{1}$ I3S - Instituto de Investigação e Inovação em Saúde, Universidade do Porto, Portugal

${ }^{2}$ INEB - Instituto de Engenharia Biomédica, Universidade do Porto, Portugal ${ }^{3}$ Instituto de Ciências Biomédicas Abel Salazar, Universidade do Porto, Portugal

${ }^{4}$ IBMC - Instituto Biologia Molecular e Celular, Universidade do Porto, Portugal

${ }^{\sharp}$ Current address: Institute of Orthopaedic Research and Biomechanics, University of Ulm, Ulm, Germany

\section{Abstract}

Mesenchymal stem/stromal cells (MSCs) have been increasingly used in clinical trials for low-back pain (LBP) and intervertebral disc (IVD) degeneration with promising results. Their action mechanisms are not fully understood, but they reduce IVD pro-inflammatory markers in a pro-inflammatory/degenerative IVD microenvironment. In this study the therapeutic potential of the MSC secretome, as an alternative cell-free approach for treating degenerated IVDs, was examined. Human bone marrow-derived MSC secretome (MSCsec) was collected after $48 \mathrm{~h}$ of preconditioning in IL-1 $\beta(10 \mathrm{ng} / \mathrm{mL})$ and low oxygen $\left(6 \% \mathrm{O}_{2}\right)$, mimicking the degenerative IVD. IL-1 $\beta$-pre-conditioning of MSCs increased secretion of pro-inflammatory markers hIL-6, hIL-8, hMCP-1, etc. The therapeutic effect of MSCsec was tested in a pro-inflammatory/degenerative IVD ex vivo model. MSCsec down-regulated IVD gene expression of pro-inflammatory cytokines $(b I L-6, b I L-8)$ and matrix degrading enzyme $b M M P 1$, while $b M M P 3$ and $b T I M P 2$ were up-regulated, at $48 \mathrm{~h}$. After $14 \mathrm{~d}$, MSCsectreated IVDs revealed increased aggrecan deposition, although no differences in other ECM components were observed. Protein analysis of the MSCsec-treated IVD supernatant revealed a significant increase of CXCL1, MCP-1, MIP-3 $\alpha$, IL-6, IL-8 and GRO $\alpha / \beta / \gamma$ (related to TNF, NOD-like receptor and neutrophil chemotaxis signalling), and a decrease of IFN- $\gamma$, IL-10, IL-4, IL-5 and TNF- $\alpha$ (associated with T-cell receptor signalling). MSCsec-treated IVD supernatants did not promote angiogenesis and neurogenesis in vitro. Overall, MSCsec can be a safe therapeutic approach, presenting a strong immunomodulatory role in degenerated IVD while potentiating aggrecan deposition, which can open new perspectives on the use of MSCsec as a cell-based/ cell-free therapeutic approach to LBP.

Keywords: Mesenchymal stem cells, degenerative intervertebral discs, immunomodulation, secretome, paracrine signalling, extracellular matrix.

*Address for correspondence: Dra. Raquel Madeira Gonçalves, I3S - Rua Alfredo Allen 208, 4200-135 Porto, Portugal.

Telephone number: +351 220408800 Email: raquelg@ineb.up.pt

Copyright policy: This article is distributed in accordance with Creative Commons Attribution Licence (http://creativecommons.org/licenses/by-sa/4.0/).

\begin{tabular}{|c|c|c|c|}
\hline & List of Abbreviations & $\begin{array}{l}\text { CD90 } \\
\text { COL1 }\end{array}$ & $\begin{array}{l}\text { THYmocyte differentiation antigen } 1 \\
\text { collagen type I }\end{array}$ \\
\hline ACAN & aggrecan & COL2 & collagen type II \\
\hline ADAMTS 5 & a disintegrin and metalloproteinase with & CXCL1 & chemokine (C-X-C motif) ligand 1 \\
\hline & thrombospondin motifs 5 & $\mathrm{DAB}$ & diaminobenzidine tetrahydrochloride \\
\hline $\mathrm{AF}$ & annulus fibrosus & DAPI & 4',6-diamidino-2-phenylindole \\
\hline ASCs & adipose-derived stem cells & $\mathrm{dDC}$ & degenerated disc cells \\
\hline ASCs-CM & adipose-derived stem cells conditioned & DMEM & Dulbecco's modified Eagle's medium \\
\hline AVCS-Civi & medium & DMMB & 1,9-dimethyl-methylene blue zinc \\
\hline $\mathrm{b}$ as prefix & bovine & & chloride double salt \\
\hline BDNF & brain-derived neurotrophic factor & DRG & dorsal root ganglion \\
\hline $\mathrm{BM}$ & bone marrow & ECGS & endothelial cell growth supplement \\
\hline BSA & bovine serum albumin & $\mathrm{ECM}$ & extracellular matrix \\
\hline CD105 & endoglin & ELISA & enzyme-linked immunosorbent assay \\
\hline CD73 & ecto-5'-nucleotidase & FBS & foetal bovine serum \\
\hline
\end{tabular}




\begin{tabular}{|c|c|}
\hline FDU & 5-fluoro-2'-deoxyuridine \\
\hline FGF & fibroblast growth factor \\
\hline GAG & glycosaminoglycan \\
\hline GAPDH & $\begin{array}{l}\text { glyceraldehyde 3-phosphate } \\
\text { dehydrogenase }\end{array}$ \\
\hline GCP-2 & granulocyte chemotactic protein 2 \\
\hline GDNF & glial cell line-drived neurotrophic factor \\
\hline GRO $\alpha / \beta / \gamma$ & growth-related oncogen $\alpha / \beta / \gamma \mathrm{NGF}$ \\
\hline NGF & nerve growth factor \\
\hline HBSS & Hank's balanced salt solution \\
\hline$h$ as prefix & human \\
\hline HUVECs & human umbilical vein endothelial cells \\
\hline IBFBP-2 & $\begin{array}{l}\text { insulin-like growth factor binding } \\
\text { protein } 2\end{array}$ \\
\hline $\operatorname{IFN} \gamma$ & interferon-gamma \\
\hline IGF-1 & insulin-like growth factor 1 \\
\hline IGFBP-1,3,4 & $\begin{array}{l}\text { insulin-like growth factor binding } \\
\text { protein } 1,3,4\end{array}$ \\
\hline IL- & interleukin- \\
\hline IQR & interquartile range \\
\hline ISCT & International Society for Cellular Therapy \\
\hline IVD & intervertebral disc \\
\hline LBP & low-back pain \\
\hline MCP-1,2,3 & monocyte chemoattractant protein- $1,2,3$ \\
\hline MIG & monokine induced by gamma interferon \\
\hline MIP-1ठ & macrophage inflammatory protein $1 \delta$ \\
\hline MIP-3 $\alpha$ & macrophage inflammatory protein $3 \alpha$ \\
\hline MMPs & matrix metalloproteinases \\
\hline MSCs & mesenchymal stem/stromal cells \\
\hline MSCsec & MSCs secretome \\
\hline NOD & $\begin{array}{l}\text { nucleotide-binding oligomerisation } \\
\text { domain }\end{array}$ \\
\hline NP & nucleus pulposus \\
\hline NT3, 4 & neurotrophin 3, 4 \\
\hline $\mathrm{P} / \mathrm{S}$ & penicillin/streptomycin \\
\hline PARC & $\begin{array}{l}\text { pulmonary and activation-regulated } \\
\text { chemokine }\end{array}$ \\
\hline PBS & phosphate-buffered saline \\
\hline PFA & paraformaldehyde \\
\hline $\mathrm{PGE}_{2}$ & prostaglandin $\mathrm{E}_{2}$ \\
\hline PI & propidium iodide \\
\hline PLGF & placental growth factor \\
\hline RANTES & $\begin{array}{l}\text { regulated on activation, normal } \mathrm{T} \text { cell } \\
\text { expressed and secreted }\end{array}$ \\
\hline RGB & red-green-blue \\
\hline SDF-1 $\alpha$ & stromal cell-derived factor 1-alpha \\
\hline sGAG & sulphated glycosaminoglycans \\
\hline TGF $\beta 1$ & transforming growth factor beta- 1 \\
\hline TIMP & tissue inhibitors of metalloproteinases \\
\hline TNF & tumour necrosis factor \\
\hline Th1\&17 cells & T helper cells, types 1 and 17 \\
\hline VEGF-A & vascular endothelial growth factor-A \\
\hline
\end{tabular}

\section{Introduction}

For decades, LBP has been considered the world's leading disorder in number of years lived with disability, currently affecting up to $70-85 \%$ of the world population (James et al., 2018). The aetiology of this disease is complex and with many possible catalysts, but still, $40 \%$ of LBP episodes are related to IVD degeneration (DePalma et al., 2011). The IVD degenerative process, believed to originate in the NP (Raj, 2008), involves a myriad of different events whose connection and causal order are still not completely understood. IVD cells produce increased levels of the pro-inflammatory cytokines TNF, IL-1 $\alpha$, IL-1 $\beta$, IL-6 and IL-17 (Risbud and Shapiro, 2014) and
MMPs and aggrecanases, that leads to a degradation of ECM resulting in loss of disc height and integrity (Rannou et al., 2001). It also induces the production of breakdown products that cause an acidification of the IVD microenvironment, leading to cell death (Quero et al., 2013). Furthermore, the local production of pro-inflammatory cytokines also attracts leukocytes from the nearby regions, as well as invading nerves and blood vessels, to the physiologically avascular/ aneural NP (Ito and Creemers, 2013). This invasion is believed to lead to the development of discogenic pain, despite some contradictory reports (Binch et al., 2015).

Current treatments for LBP comprise conservative approaches that are unable to resolve its underlying cause, or surgical interventions that are prone to accelerate the degenerative processes of adjacent anatomical structures (Harrop et al., 2008). Therefore, alternative therapies have been highly sought after. Cell therapies, particularly those using MSCs, have been extensively studied in the context of IVD degeneration (Sakai and Schol, 2017). MSCs, as well as their secretome, can potentiate tissue regeneration and modulate the immune response in many pathological conditions (Ferreira et al., 2018), including closely related scenarios such as osteoarthritis-induced cartilage damage (Khatab et al., 2018). This therapeutic effect has been shown to be susceptible to improvement by preconditioning of the cells with specific microenvironmental factors (oxygen and nutrients abundance, culture medium $\mathrm{pH}$, presence of specific soluble factors) (Ferreira et al., 2018). In the context of IVD degeneration, many reports have added to the potential MSCs have as a viable therapeutic approach. Such literature has demonstrated the ability of MSCs to differentiate into NP-like cells in-vivo, capable of contributing to the production of discogenic ECM (Wei et al., 2014). Others indicate that MSCs act by preventing the loss of ECM and, consequently, some disc height reduction in in vivo models of IVD degeneration (Cunha et al., 2017; Hiyama et al., 2008; Sakai et al., 2003). Additionally, MSCs have been observed to protect IVD cells from apoptosis (Chen et al., 2017; Cheng et al., 2018) and reported as safe in clinical trials, having provided symptomatic pain relief in 12 patients (Orozco et al., 2011; Yoshikawa et al., 2010).

The authors have previously shown that MSCs can modulate the intense production of catabolic/ pro-inflammatory factors by degenerative IVD cells (Teixeira et al., 2018), in a bovine IVD ex vivo model under pro-inflammatory/degenerative conditions (Teixeira et al., 2016). In this model, MSCs were able to downregulate the expression of IL-6, IL-8 and TNF- $\alpha$ as well as MMPs in IVD cells (Teixeira et al., 2018). The authors and others hypothesise that MSCs act through a paracrine mechanism that mediates the discs' response (Miyamoto et al., 2010). This is in line with the increasing number of publications referring the importance of the MSCsec (Ferreira et al., 2018). On the other hand, their capacity to survive 
for a long time in the harsh microenvironment of the degenerative IVD and actively differentiate into cells from the injured/diseased/degenerated tissues is still under scrutiny, with opposing data having been released, which also contributes to the hypothesis that the secretome and not the actual presence of cells is the relevant factor (Cunningham et al., 2018). With emphasis placed on how the surrounding microenvironment greatly influences the composition of MSC secretome (Ferreira et al., 2018), the authors hypothesise that the MSCs action in the degenerated IVD is mainly mediated by their secretome, thus taking the first steps into the possibility for a cellbased/cell-free therapeutic approach to the problem. To test this hypothesis, the response of degenerated
IVD to MSCsec, using a previously established and validated (Teixeira et al., 2016) pro-inflammatory/ degenerative IVD ex vivo model, was investigated.

\section{Materials and Methods}

Ethics approval and consent to participate

All the biological samples used in this work were obtained with the ethical approval of the Portuguese authorities and manipulated according to official guideline abiding protocols. BM samples used for the isolation of human MSCs were collected from patients of both genders aged 18-45 years old, by the Orthopaedics Service according to the rules of

a

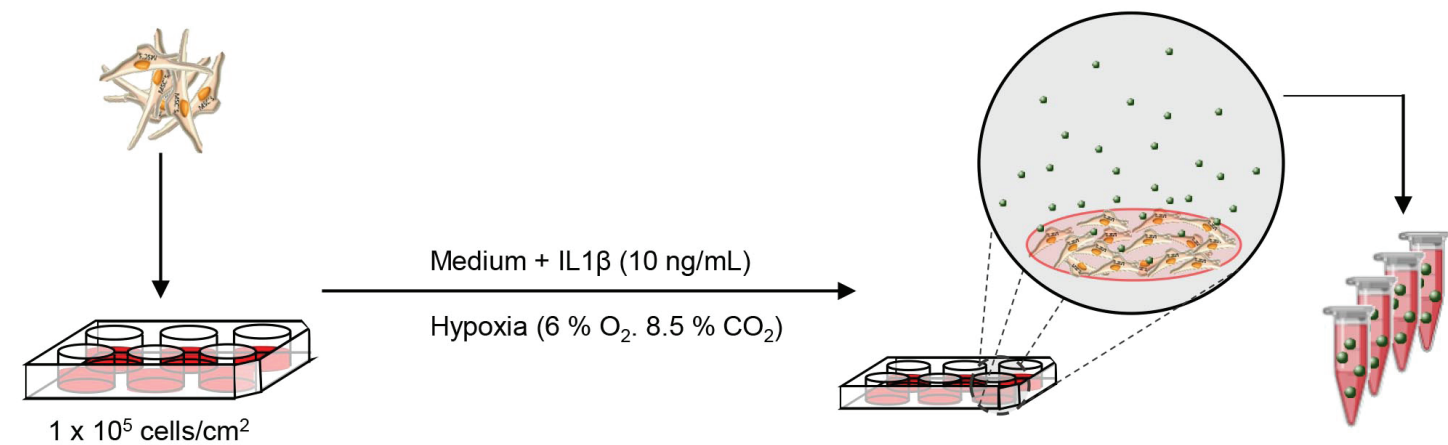

MSCs
MSCs $\begin{gathered}\text { Soluble factors } \\ \text { produced by MSCs }\end{gathered}$

b

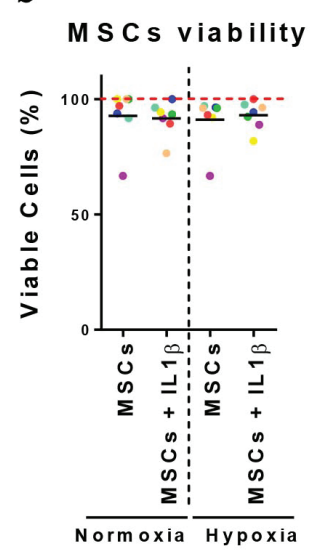

M S C s m etabolic activity

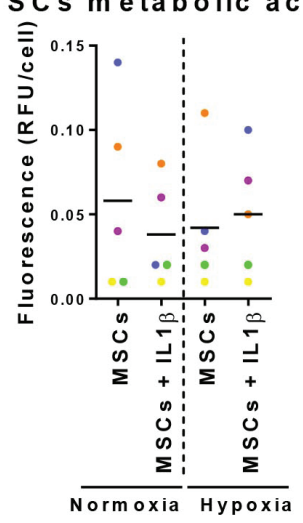

C MSCs phenotype
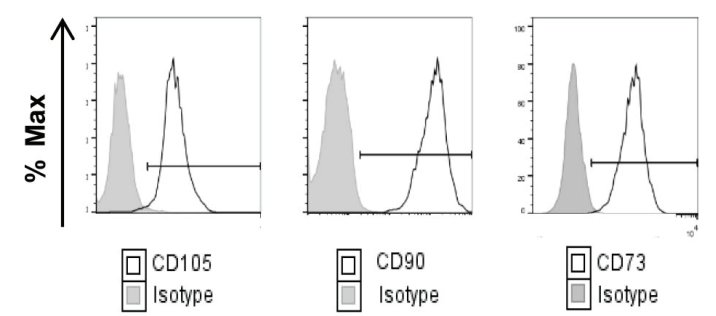

\begin{tabular}{lccc}
\multicolumn{1}{c}{$\%$} & CD105 & CD90 & CD73 \\
\hline \hline MSCs before pre-conditioning & 93.24 & 98.66 & 97.42 \\
ISCT standard & $>95 \%$ & $>95 \%$ & $>95 \%$ \\
\hline $\mathbf{N}$ & 95.67 & 98.12 & 97.10 \\
$\mathbf{N}+$ IL1 $\beta$ & 89.47 & 97.52 & 93.40 \\
$\mathbf{H}$ & 91.47 & 98.62 & 96.00 \\
$\mathbf{H}+$ IL1 $\beta$ & 91.77 & 98.62 & 97.60
\end{tabular}

Fig. 1. Effect of pre-conditioning on MSC viability, metabolic activity and phenotype. hBM-MSCs were preconditioned with or without IL-1 $\beta(10 \mathrm{ng} / \mathrm{mL})$ under normoxic $\left(21 \% \mathrm{O}_{2}\right)$ or hypoxic $\left(6 \% \mathrm{O}_{2}\right)$ conditions, in 6-well plates, for 48 h. (a) Graphical illustration of experimental setup. (b) Percentage of viable cells assessed by trypan blue exclusion assay and fluorescence levels of resorufin produced as a result of resazurin reduction by metabolically active MSC $(n=5-7)$. fluorescence levels were normalised to the total cell number cultured. (c) Flow cytometry analysis of MSCs upon pre-conditioning. Representative histogram of CD105, CD90 and CD73 expression of MSCs and quantitative analysis of the percentage of MSCs exhibiting surface expression of CD90, CD105, CD73 $(n=1)$. All the results are presented as box and whiskers plots with representation of median, min and max values and statistical analysis was performed using the non-parametric paired Wilcoxon test. 
a

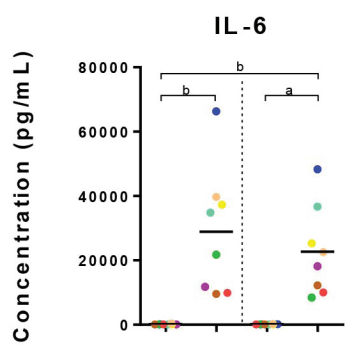

IL -8
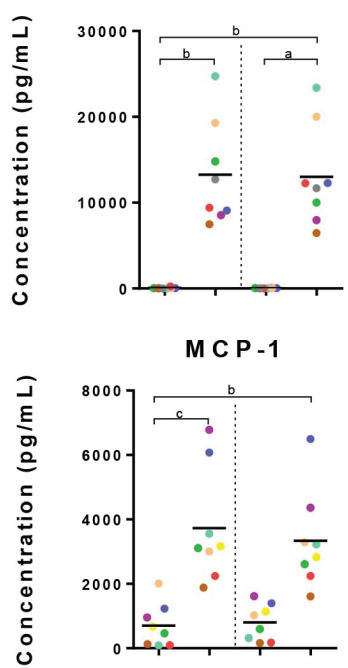

RANTES
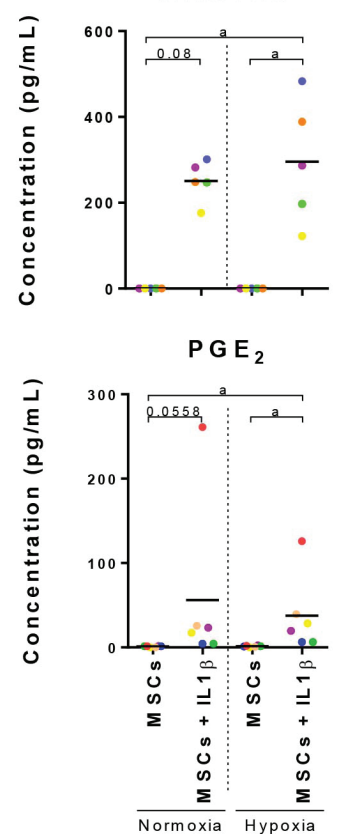

b

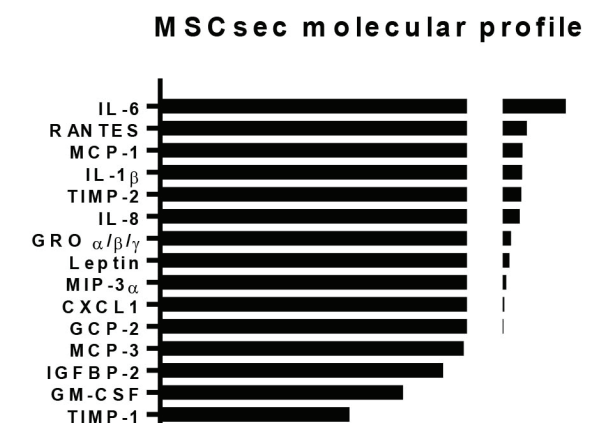

gen in

OPN

$M I P-1 \beta$
IGFB -1

VEGF-A

IGFBP-3

M $-C S F-$

$M-C S F$
$C X C L 5$

N T -4

TGF $-\beta 2$

$T G F-\beta 2$
$P L G F$
$M C P-2$

$M C P-2$

MIF

$B$ DNF

TAR C

IL -7

$N$ AP -2

B L C

IGHT

IL -16

F GF -6

F GF -9

Eotaxin $2=$

IL -3

H G F

IF $\mathbf{N}-\gamma$

FLT-3 Ligand
SDF-1

S D F -1 $\alpha$
N T -3

PDGF-BB

PAR C

F GF -7

GDN F

TN F $-\beta$

IG F - 1

$C$ k $-\beta$ 8-1

IL $-1 \alpha=$

$M D C$

taxin 1

IL - 15
$\operatorname{taxin} 3$

$S C F$

Fractalkine
TGF $-\beta 3$

TGF - $\beta 3$
M IG

MIG
TNF - $\alpha$
TGF - $\beta 1$

TGF $-\beta 1$
G-C SF

G -C SF
MIP-1

MIP-18

$\mathrm{I}-309$
$\mathrm{IL}-13$

IL $-2=$

IL -12 p $40 / \mathrm{p} 70=$

IL -4

MSCsec

DAVID clusters Soluble factors

upregulated

GRO $\alpha / \beta / \gamma$. IL-1 $\beta$. IL-6.

IL-8. RANTES. MIP-3a

TNF signalling pathwayd

Neutrophil chemotaxis positive regulation ${ }^{b}$

GRO $\alpha / \beta / y$. IL-8

GRO $\alpha / \beta / Y$. IL-1 $1 \beta$. IL-8.

Inflammation ${ }^{b}$

MCP-1. RANTES. MIP-

$3 \alpha$

NOD-like receptor

signalling pathwayb

GRO $\alpha / \beta / y . ~ I L-1 \beta . ~ I L-6$.

IL-8. MCP-1

Cellular response to

FGFa

IL-8. MCP-1. RANTES

Signal density

Fig. 2. The effect of pre-conditioning on MSCsec composition. The secretome of hBM-MSCs preconditioned with or without IL-1 $\beta(10 \mathrm{ng} / \mathrm{mL})$ under normoxic $\left(21 \% \mathrm{O}_{2}\right)$ or hypoxic $\left(6 \% \mathrm{O}_{2}\right)$ conditions, in 6-well plates, for $48 \mathrm{~h}$ was collected and analysed for its content. (a) Inflammatory cytokines concentration in MSCsec. IL-6, IL-8, MCP-1, RANTES, PGE 2 were quantified in culture supernatants by ELISA $(n=5-8)$. All the results are presented as box and whiskers plots with representation of median, min and max values and statistical analysis was performed using the non-parametric paired Wilcoxon test, a $(p<0.05)$; b $(p<0.01)$, c $(p<0.001)$. (b). Relative concentration of 80 molecules in the MCSsec, represented by their absolute signal density values (pool of 4 donors). (c) Ontology terms significatively enriched in the functional clusters obtained by the analysis of the 10 most concentrated molecules (out of the 80 analysed) with the DAVID Functional Annotation Tool software. Statistical significance was calculated by the DAVID Functional Annotation Tool software considering a $95 \%$ confidence levels, a $(p<0.05)$; b $(p<0.01)$; c $(p<0.001)$; $\mathrm{d}(p<0.0001)$. 
the ethical commission of Centro Hospitalar S. João and after informed consent of the patients. Bovine tails were obtained from the local slaughterhouse Carnes Landeiro SA, with the ethical approval of Portuguese Agency for Animal Welfare (DireçãoGeral de Alimentação e Veterinária, DGAV). Embryonic DRGs were acquired from 16-18 d murine embryos according to animal procedures approved by the INEB/IBMC ethics committee and by DGAV in accordance with the EU Directive (2010/63/EU) and Portuguese law (DL 113/2013).

MSCs preconditioning and secretome production Human BM was harvested from donors undergoing hip replacement or knee surgery and MSCs were isolated by Ficoll gradient centrifugation and adherence to plastic, and routinely cultured, as previously reported (Almeida et al., 2012). MSCs phenotype and multilineage differentiation potential were previously assessed according to the guidelines of the International Society of Cell Therapy (Dominici et al., 2006), and as established in the authors' lab (Almeida et al., 2012). At least 3 different donors of MSCs in passages 4-9 were used for the experiments. Human BM-derived MSCs were seeded onto 6-well tissue culture plates $\left(1 \times 10^{6}\right.$ cells per well), in lowglucose DMEM (Corning, New York, NY, USA), supplemented with $10 \%$ heat-inactivated FBS, MSCs qualified (Gibco, Waltham, MA, USA) and $1 \% \mathrm{P} / \mathrm{S}$, and left to adhere at $37^{\circ} \mathrm{C}$ with $21 \% \mathrm{O}_{2}$ for $24 \mathrm{~h}$. After this period, cell culture medium was replaced with $5 \mathrm{~mL}$ of fresh medium, alone or supplemented with recombinant human IL-1 $\beta$ (10 ng/mL) (PeproTech, Cranbury, NJ, USA), and MSCs were cultured at $37^{\circ} \mathrm{C}$ either in $6 \% \mathrm{O}_{2}+8.5 \% \mathrm{CO}_{2}$ (hypoxia) or $21 \%$ $\mathrm{O}_{2}+5 \% \mathrm{CO}_{2}$ (normoxia). Graphical representation of the experimental procedure can be found in Fig. 1a. MSCsec was collected after $48 \mathrm{~h}$ [the timepoint previously used in which MSCs revealed to be immunomodulatory in this context (Teixeira et al., 2018)] and the cells harvested for further processing. MSCs viability was ascertained by trypan blue dye-exclusion assay and mitochondrial metabolic activity of MSCs was assessed by resazurin-reduction assay, as previously described (Teixeira et al., 2018). MSCs phenotype was analysed by flow cytometry according to the ISCT criteria (Dominici et al., 2006), as established in the author's group (Almeida et al., 2012).

MSCsec collected was centrifuged at $1,800 \times g$ for $5 \mathrm{~min}$, at $4{ }^{\circ} \mathrm{C}$, to remove cell debris. Both conditioned media and cell pellets were then stored at $-80^{\circ} \mathrm{C}$ until further use. MSCsec was assessed for the following growth factors/cytokines: $\mathrm{PGE}_{2}$ (Arbor Assays), IL-8 (PeproTech), IL-6 (PeproTech), MCP-1 (PeproTech) and RANTES (PeproTech) (Fig. 2a). For that, human ELISA kits (Arbor Assays, Ann Arbor, MI, USA and PeproTech) were used according to the manufacturer's instructions.

\section{Pro-inflammatory/degenerative bovine IVD organ culture treatment with MSCsec}

Bovine IVDs were isolated from tails of young animals ( $<1$ year old) up to $3 \mathrm{~h}$ post-slaughter and cultured, as previously described (Teixeira et al., 2016). Briefly, after removing the tissue surrounding the discs, these were dissected from the tails with a scalpel and the centre part of the NP tissue was collected, using a $9 \mathrm{~mm}$-puncher. The NP explants were cultured in 6-well plates under $0.46 \mathrm{MPa}$ static loading in $5 \mathrm{~mL}$ of low-glucose DMEM medium supplemented with $5 \% \mathrm{FBS}, 1 \% \mathrm{P} / \mathrm{S}, 0.5 \%$ amphotericin B and osmolarity adjusted to IVD-physiological $400 \mathrm{mOsm}$ by addition of $1.5 \% \mathrm{NaCl} / \mathrm{KCl}(5 \mathrm{MOL} / \mathrm{L} / 0.4 \mathrm{~mol} / \mathrm{L})$. Culture conditions were kept at $37^{\circ} \mathrm{C}$ under reduced oxygen atmosphere $\left(6 \% \mathrm{O}_{2}, 8.5 \% \mathrm{CO}_{2}\right)$ and saturated humidity with medium changes at every $2 \mathrm{~d}$. At the fifth day of culture, IVDs were needle-punctured with a $21 \mathrm{G}$ needle to induce degeneration and the culture medium was supplemented with $10 \mathrm{ng} / \mathrm{mL}$ of recombinant human IL-1 $\beta$ (PeproTech). $3 \mathrm{~h}$ later, the culture medium was replaced by MSCsec further supplemented with $10 \mathrm{ng} / \mathrm{mL}$ of IL-1 $\beta$. For short-term IVDs organotypic culture ( $48 \mathrm{~h}$ ), the IVD cells were isolated from the tissue by enzymatic digestion with $0.2 \%$ collagenase type IA (Sigma-Aldrich, St. Louis, MO, USA) in low-glucose DMEM supplemented with $1 \% \mathrm{P} / \mathrm{S}$ and $0.5 \%$ amphotericin $\mathrm{B}$, at $37^{\circ} \mathrm{C}$, overnight, with magnetic agitation. These cells were then passed through a $100 \mu \mathrm{m}$ cell strainer, washed with PBS $1 \times$ and stained for PI and Annexin V expression according to the kit's manufacturer's instructions (BD, Pharmigen, San Diego, CA, USA) before analysis by flow cytometry using the BD FACSCANTO ${ }^{\mathrm{TM}}$ II cell analyser (Fig. 3b). The medium from the IVD culture (IVD conditioned medium) was also collected and stored at $-20^{\circ} \mathrm{C}$. For long-term IVDs organotypic culture (14 d), the culture medium was replaced ( $25 \%$ ) every $4-5 \mathrm{~d}$, without new addition of IL-1 $\beta$. At day 14, IVDs were collected for histological analysis (Fig. 4a). Non-stimulated IVDs and IVDs punctured and stimulated with $10 \mathrm{ng} / \mathrm{mL}$ of IL-1 $\beta$ were used as controls in all experiments. All of the IVDs cultures were maintained in culture at $37^{\circ} \mathrm{C}$, $6 \% \mathrm{O}_{2}$ and $8.5 \% \mathrm{CO}_{2}$.

\section{Analysis of MSCsec and IVD conditioned media}

The cytokine content of MSCsec and IVD conditioned media was analysed using the Human Cytokine Array C5 (RayBiotech, Peachtree Corners, GA, USA), following the manufacturer's protocol. For that, a pool of MSCsec from 4 different donors and a pool of conditioned media collected from 4 distinct IVD cultures stimulated with: i) needle-puncture + IL-1 $\beta$ (IL-1 $\beta$ ) and ii) needle-puncture + IL-1 $\beta+$ MSCsec (IL-1 $\beta+$ MSCsec) were mixed and analysed in the membrane array. Chemiluminescent signal was detected in a Chemidoc XRSp image analyser (BioRad, Hercules, CA, USA) with an exposure time 
a

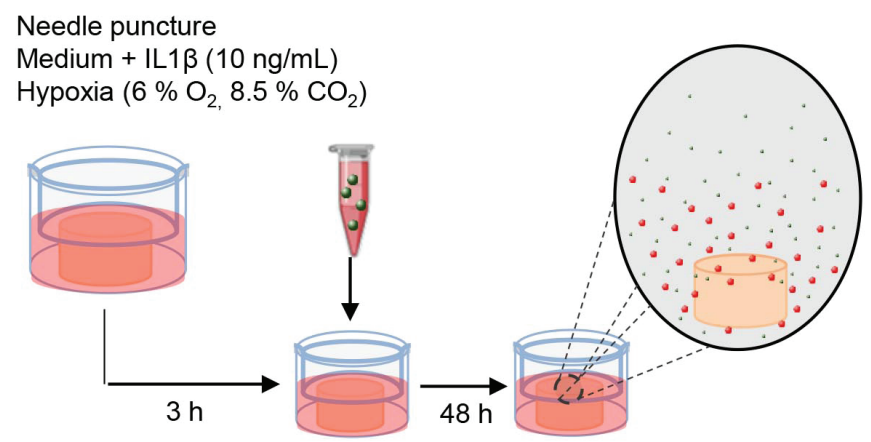

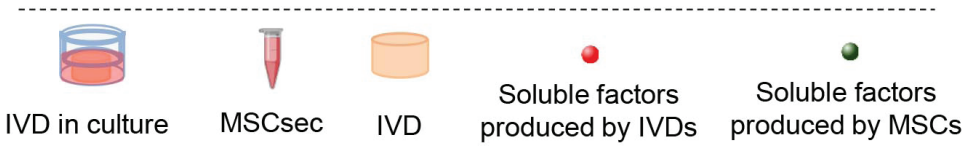

b.1

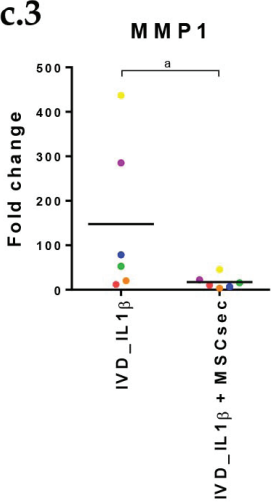

c.1

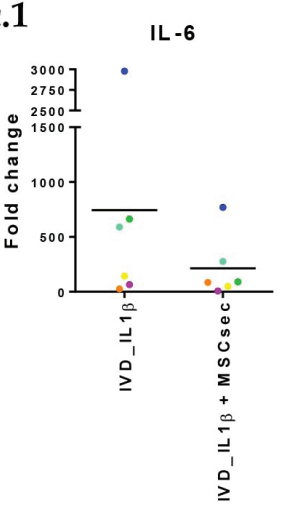

c. 2

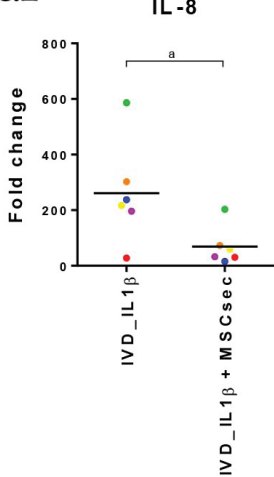

c. 6

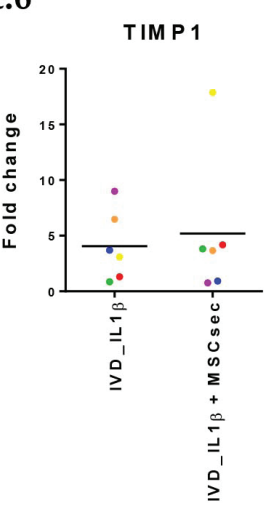

c. 7

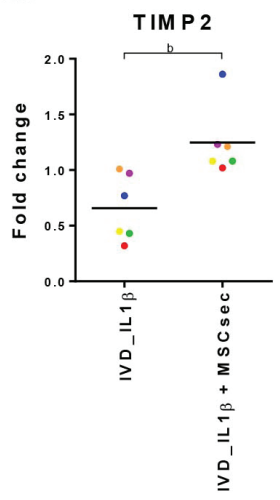

c. 8

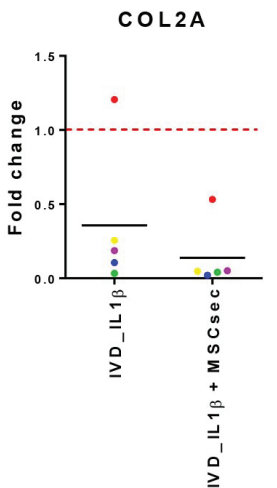

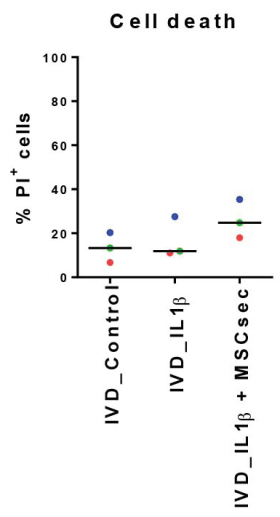

c.4

b. 2

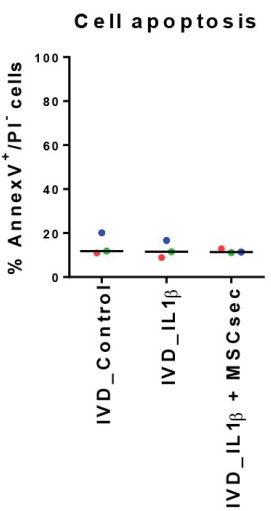

c.5
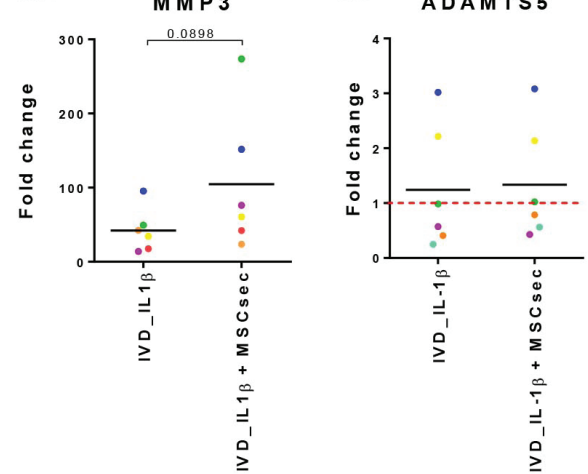

Fig. 3. MSCsec role on IVD degenerative status at $48 \mathrm{~h}$ post degenerative stimulus. Pro-inflammatory/ degenerative bIVDs were generated by needle puncture and culture with IL-1 $\beta$ under hypoxia, followed by short-term culture in the presence of MSCsec collected from pre-conditioned MSCs. (a) Graphical illustration of the experimental setup. (b) Cell viability in response to the pro-inflammatory stimulus/treatment with MSCsec was assessed by flow cytometry analysis of Anexin/PI staining for the percentage of (c.1) dead cells and (b.2) cells in apoptosis. (c) After $48 \mathrm{~h}$, the inflammatory status of IVD was evaluated by analysing the gene expression levels of pro-inflammatory cytokines (c.1) bIL-6 and (c.2) bIL-8, matrix degrading enzymes (c.3) $b M M P 1$, (c.4) $b M M P 3$ and (c.5) bADAMTS5, matrix degrading enzymes inhibitors (c.6) bTIMP1 and (c.7) $b T I M P 2$ and matrix components (c.8) $b C O L 2$ and (c.9) $b A C A N$ were assessed and normalised to $b G A P D H$. The results are presented as fold change to control IVDs (control level $=1)(n=5-6)$. All the results are presented as box and whiskers plots with representation of median, min and max values and statistical analysis was performed using non-parametric paired Wilcoxon test, $\mathrm{a}(p<0.05)$; $\mathrm{b}(p<0.01), \mathrm{c}(p<0.001)$. 
of $5.0 \mathrm{~s}$. Membrane array images were analysed using ImageLab 6.0 software (Bio-Rad). Briefly, reference circles were equally defined for all the spots in the array and the mean spot pixel density calculated. The signal densities were normalised to the background. Results were then analysed using the Functional Annotation Clustering Tool from the DAVID Database (Huang et al., 2007), whose output was composed of a list of ontology terms organised in functional clusters with attached statistical significance values for its enrichment relative to the expected ratio of the used background (total of molecules analysed). When possible, a comparative analysis was conducted by calculating the treatment/ degenerative control ratio, which expresses the up- or down-regulation of certain factors present in the degenerative NP due to treatment with MSCsec related to the untreated degenerative/proinflammatory IVD. Only molecules with a differential protein expression ratio cut-off $>5$ and $<-5$ were considered for analysis. These thresholds were defined considering the physiological significance of the observed differences in comparison to the global differences. For the conditions compared, most of the molecules analysed were altered far beyond the physiologically relevant thresholds previously used by the authors' group (-1.3/- 1.5 to $+1.3 /+1.5)$ (Caldeira et al., 2017; Silva et al., 2017). Comparatively, the increase in the cut-off values (to 5 and -5) help to decrease the number of false positives (Gregori et al., 2013). These conservative values also reduce the number of candidate molecules; therefore, focusing the consequent analysis only on the most affected factors. The analysis of the MSCsec was exploratory, without any comparison to another experimental group being examined. Instead, the top 10 most prevalent molecules detected were selected and then tested with the Functional Annotation
Clustering Tool from the DAVID Database. This test was performed to ascertain any statistically relevant enriched functional clusters to which the most MSCsproduced molecules were linked.

\section{Gene expression analysis of IVD}

At $48 \mathrm{~h}$ after degenerative stimulation and culture with MSCsec, IVD total RNA was extracted and reverse transcribed into cDNA for gene expression analysis. For RNA extraction from the IVD explants, the tissue was chopped into very small fragments using a scalpel and enzymatically digested for $1 \mathrm{~h}$ with $2 \mathrm{mg} / \mathrm{mL}$ protease from Streptomyces griseus (SigmaAldrich) in DMEM, under agitation (50 rpm), at $37^{\circ} \mathrm{C}$. The digestion was inhibited by the addition of FBS $(10 \mu \mathrm{L} / \mathrm{mL})$ (Capricorn Scientific, Ebsdorfergrund, Hessen, Germany) and the remaining tissue was washed twice with cold PBS $1 \times$. The tissue pellet was then snap frozen in liquid nitrogen, thawed, and resuspended in TRIzol reagent (Invitrogen, Waltham, MA, USA). The protocol recommended by the manufacturer was followed up to the collection of the aqueous phase containing the RNA. This phase was carefully removed and, after the addition of isopropanol, transferred to the binding columns of the ReliaPrep RNA Cell Miniprep System (Promega, Madison, WI, USA), which was used to purify total RNA, according to manufacturer's instructions. RNA was quantified using a NanoDrop spectrophotometer (Infinite M200; Tecan, Mannerdorf, Switzerland). RNA quality was confirmed by determining the RNA integrity ratio in a bioanalyser, using the RNA 6000 Pico Kit.

Total RNA from IVD cells $(\sim 500$ ng per IVD sample) was reverse transcribed into cDNA using the SuperScript III RT Kit (Invitrogen) complemented with deoxynucleotide mix $(10 \mathrm{mmol} / \mathrm{L})$ and random hexamer primers $(50 \mu \mathrm{mol} / \mathrm{L})$. The obtained $\mathrm{cDNA}$

Table 1. List of primers used for the gene expression analysis.

\begin{tabular}{|c|c|c|c|}
\hline Gene & Sequence (forward and reverse primer) & $\begin{array}{l}\text { Amplicon } \\
\text { length (bp) }\end{array}$ & $\begin{array}{c}\text { NCBI reference } \\
\text { sequence }\end{array}$ \\
\hline$b G A P D H$ & $\begin{array}{l}\text { Fw: 5'-GAA GGT GAA GGT CGG AGT C-3' } \\
\text { Rv: 5'-GAA GAT GGT GAT GGG ATT TC-3' }\end{array}$ & 224 & J04038 \\
\hline$b I L-6$ & $\begin{array}{l}\text { Fw: 5'-AGG AGA CTT GCC TGG TGA AA-3' } \\
\text { Rv: 5'-CAG GGG TGG TTA TTG CAT CT-3' }\end{array}$ & 180 & NM_000600 \\
\hline$b I L-8$ & $\begin{array}{l}\text { Fw: 5'-GTG CAG TTT TGC CAA GGA GT-3' } \\
\text { Rv: 5'-CTC TGC ACC CAG TTT TCC TT-3' }\end{array}$ & 196 & NM_000584 \\
\hline$b M M P 1$ & $\begin{array}{l}\text { Fw: 5'-ATG CTG AAA CCC TGA AGG TG-3' } \\
\text { Rv: 5'-CTG CTT GAC CCT CAG AGA CC-3' }\end{array}$ & 234 & NM_002421 \\
\hline$b M M P 3$ & $\begin{array}{l}\text { Fw: 5'-GGA GAT GCC CAC TTT GAT GAT-3' } \\
\text { Rv: 5'-CAT CTT GAG ACA GGC GGA AC-3' }\end{array}$ & 187 & NM_002422 \\
\hline bADAMTS5 & $\begin{array}{l}\text { Fw: 5'-CAC CTC AGC CAC CAT CAC AG-3' } \\
\text { Rv: 5'-AGT ACT CTG GCC CGA AGG TC-3' }\end{array}$ & 152 & NM_001166515.1 \\
\hline bCollagen II & $\begin{array}{l}\text { Fw: 5'-CGC ACC TGC AGA GAC CTG AA-3' } \\
\text { Rv: 5'-TCT TCT TGG GAA CGT TTG CTG G-3' }\end{array}$ & 162 & XM_056481 \\
\hline bAggrecan & $\begin{array}{l}\text { Fw: 5'-TCT GTA ACC CAG GCT CCA AC-3' } \\
\text { Rv: 5'-CTG GCA AAA TCC CCA CTA AA-3' }\end{array}$ & 199 & XM_007701 \\
\hline bTIMP1 & $\begin{array}{l}\text { Fw: 5'-GAC CGC AGA AGT CAA TGA AA-3' } \\
\text { Rv: 5'-GAA ACT CCT CAC TGC GGT TC-3' }\end{array}$ & 176 & NM_174471.3 \\
\hline bTIMP2 & $\begin{array}{l}\text { Fw: 5'-AGG GCC AAA GCA GTC AAT AA-3' } \\
\text { Rv: 5'-AGA GGA GGG GGC TGT GTA GA-3' }\end{array}$ & 150 & NC_037346.1 \\
\hline
\end{tabular}


a
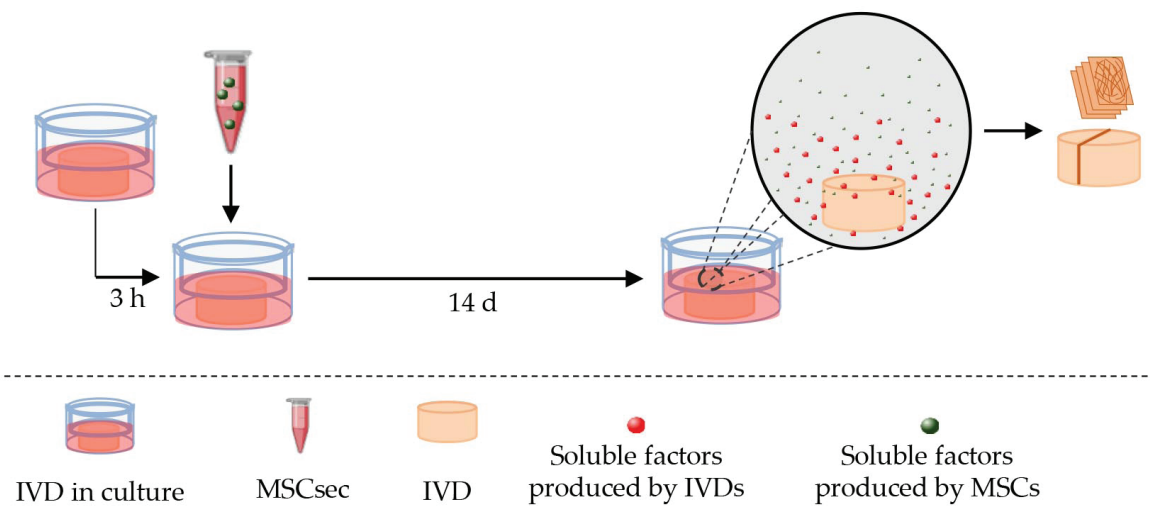

b

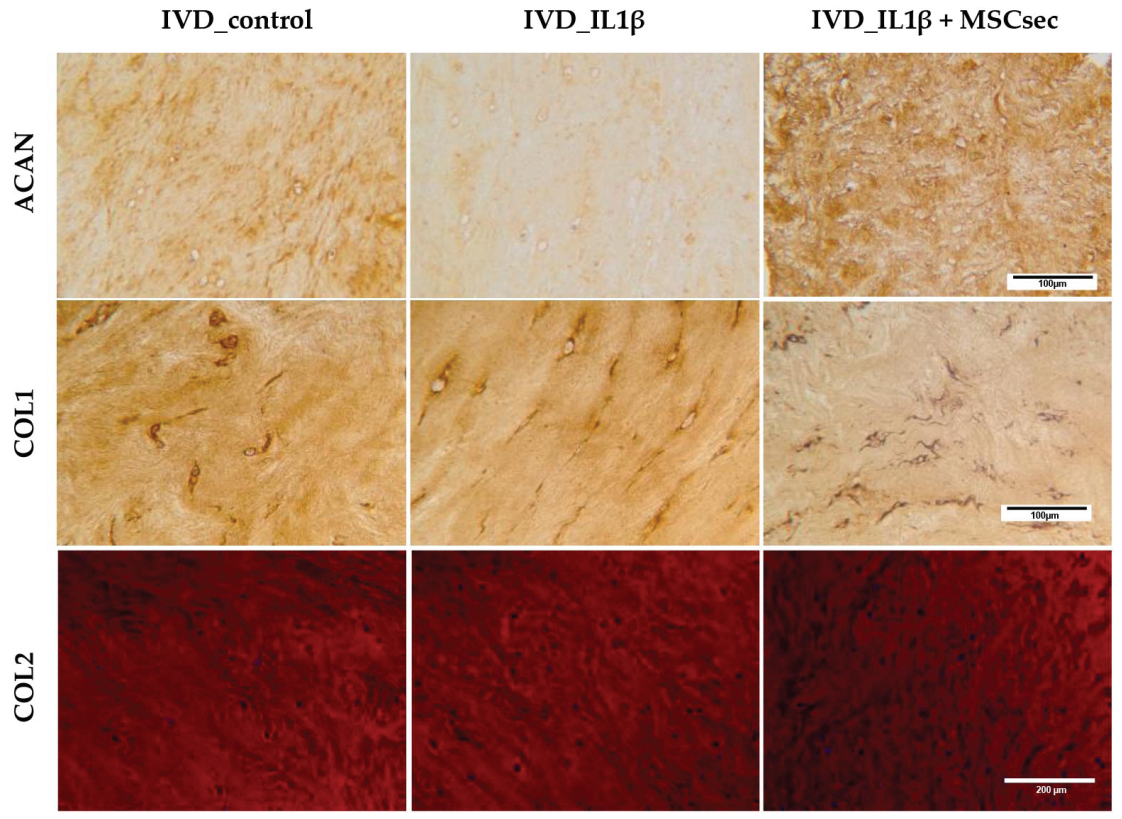

c
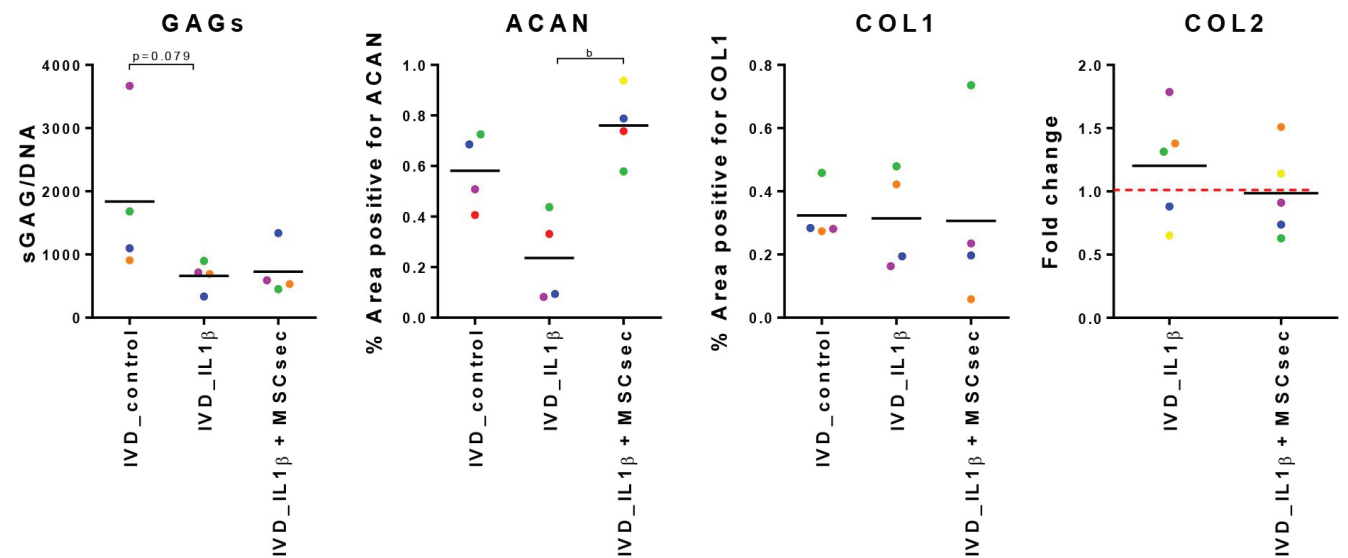

Fig. 4. MSCsec role on the ECM of proinflammatory/degenerative IVDs. Pro-inflammatory/degenerative bIVDs generated by needle puncture and culture with IL-1 $\beta$ under hypoxia, were cultured long-term in the presence of MSCsec collected from pre-conditioned MSC. (a) Graphical illustration of the experimental setup. (b) Representative images of sagittal sections of IVD explants stained for ACAN (scale bar $=100 \mu \mathrm{m}$ ), COL1 (scale bar $=100 \mu \mathrm{m}$ ) and COL2 (scale bar $=200 \mu \mathrm{m})$. (c) Biochemical analysis of IVD explants' sGAG, after $14 \mathrm{~d}$ in culture, normalised to the control $(n=4)$. Quantification of total positive stained area for ACAN and COL1 expression $(n=4)$; quantification of COL2 fluorescence intensity normalised to control (dashed line) $(n=5)$. Results are presented as box and whiskers plots with representation of median, min and max values and statistical analysis was performed using non-parametric Kruskal-Wallis and Dunn's multiplecomparison tests. a $(p<0.05) ; \mathrm{b}(p<0.01)$. 
was used for qRT-PCR. Specific primer pairs for bovine IL-6, IL-8, MMP1, MMP3, TIMP1, TIMP2, COL2, ACAN, ADAMTS 5 and GAPDH, were purchased from Invitrogen (sequences available in Table 1). Reaction mixes were prepared with iTaq Universal SYBR Green Supermix (Bio-Rad), and carried out in a CFX96 Real-Time qPCR System (Bio$\mathrm{Rad}$ ). Gene expression was considered for $\mathrm{Cq}<35$. The results relative to the IVDs gene expression were analysed according to the $2^{-\triangle \mathrm{Cq}}$ method. Briefly, the average $\mathrm{Cq}$ of each sample was normalised to the respective $\mathrm{Cq}$ of the reference gene GAPDH $(\Delta \mathrm{Cq})$ and then normalised to the control sample relative to each experiment $(\triangle \Delta \mathrm{Cq})$. Final results are shown as $2^{-\Delta \Lambda \mathrm{Cq}}$. MSCs gene expression analysis final results are presented as $\Delta \mathrm{Cq}$.

\section{IVD ECM analysis}

After $14 \mathrm{~d}$ of culture, IVDs were fixed and embedded in paraffin wax for ECM analysis, as previously described (Teixeira et al., 2018). Antigen retrieval was performed in paraffin-wax sections by incubation with $20 \mu \mathrm{g} / \mathrm{mL}$ proteinase $\mathrm{K}$ solution for $15 \mathrm{~min}$ at $37^{\circ} \mathrm{C}$, followed by heat-induced antigen retrieval in boiling citrate buffer $\mathrm{pH} 6$ for $1 \mathrm{~min}$. Sections were incubated overnight, at $4{ }^{\circ} \mathrm{C}$, with one of the following primary antibodies: anti-collagen II-II6B3 (1 : 50, developed by Dr Thomas F. Linsenmayer, Developmental Studies Hybridoma Bank, University of Iowa), anti-collagen I antibody (1 : 100, \#600-401103-0.1, Rockland Immunochemicals, Inc., Limerick, PA, USA) or anti-aggrecan (1 : 50, \#sc-25674, H-300, Santa Cruz Biotechnology, Dallas, TX, USA). For the COL2 immunofluorescence, the protocol followed included a blocking step with $5 \%$ BSA in PBS for $1 \mathrm{~h}$ followed by primary antibody incubation. AlexaFluor 594-labelled goat anti-mouse (1 : 1,000, InvitrogenMolecular Probes) was used as secondary antibody. Sections were then mounted in Fluoroshield with DAPI (Sigma-Aldrich). For the staining with COL1 and ACAN, bound antibodies were revealed with DAB after incubation with Novolink ${ }^{\mathrm{TM}}$ Polymer, as described by the manufacturer (Novolink Polymer DS, \#RE7140-CE, Leica, Wetzlar, Germany). Control sections for each labelling were only incubated with secondary antibody. All samples were stained at the same time for comparison purposes. For the immunofluorescence staining, representative images of the slides (covering all section) were recorded using an inverted fluorescence microscope (Axiovert 200 M, Zeiss, Oberkochen, Germany) with the same exposure time for all samples. Fluorescence intensity was quantified using a custom-made MATLAB (The MathWorks Inc., Natick, MA, USA) script, the IntensityStatisticsMask software. Sections stained for ACAN and COL1 were imaged using a light microscope. The same lighting settings were maintained for all images to validate comparison. DAB staining area, directly proportional to ACAN deposition in the tissue, was quantified using a custom ImageJ H-DAB plugin, based on a colour deconvolution technique. The contributions of $\mathrm{DAB}$ and haematoxylin staining were calculated by digitally separating the specific RGB colour channels and quantifying the colour area in the corresponding DAB channel. After the threshold was set and applied to all images, the percentage of tissue stained was automatically calculated as being the positively stained area.

sGAG were also quantified by the DMMB assay. Briefly, IVDs were minced in very small sections and digested using proteinase $\mathrm{K}$ solution $(0.5 \mathrm{mg} /$ $\mathrm{mL}$ ) overnight at $56^{\circ} \mathrm{C}$. sGAG content was detected through the change in absorption spectrum registered after the reaction with $\mathrm{DMMB}$ dye reagent solution (Sigma-Aldrich), containing $40 \mathrm{mmol} / \mathrm{L} \mathrm{NaCl}$ (Roth, Goshen, IN, USA), $40 \mathrm{mmol} / \mathrm{L}$ glycine (Roth) and $46 \mu \mathrm{mol} / \mathrm{L}$ DMMB, previously adjusted to $\mathrm{pH}$ 3.0. Chondroitin sulphate A sodium salt from bovine trachea (Sigma-Aldrich) was used as a standard. Results were normalised to DNA content, quantified using Quant-iT PicoGreen DNA kit (Invitrogen), following the manufacturer's instructions.

\section{Angiogenic cell sprouting assay}

To assess the angiogenic potential of the conditioned media from IVD cultures, a cell sprouting assay using HUVECs was conducted (Bidarra et al., 2010). Briefly, HUVECs were seeded at $26.64 \times 10^{3}$ cells/ $\mathrm{cm}^{2}$ in a $\mu$-Slide Angiogenesis plate (\#81506, Ibidi, Fitchburg, WI, USA) on top of $10 \mu \mathrm{L}$ of pre-layered 3D Matrix Matrigel (Becton Dickinson, Franklin Lakes, NJ, USA), and incubated for $30 \mathrm{~min}$ at $37^{\circ} \mathrm{C}$. Culture medium containing an equal mixture of HUVECs culture medium (M199 medium, 10 \% FBS, 1 \% P/S, Heparin $0.1 \mathrm{mg} / \mathrm{mL}, 0.03 \mathrm{mg} / \mathrm{mL}$ ECGS) and the conditioned medium obtained from IVD cultures at $48 \mathrm{~h}$ after stimulation was added on top of the solid 3D matrix. Controls with HUVECs culture medium, MSCsec or IVD basal medium were performed. The sprouting ability of HUVECs was analysed at $12 \mathrm{~h}$ post-seeding. Images were acquired with an IN cell analyser 2000 system and processed with IN Cell Investigator software (GE Healthcare, Chicago, IL, USA). The obtained images were further analysed using ImageJ 1.52n (Wayne Rasband, National Institutes of Health, USA) by calculating the area covered by the tubular structures formed as well as by using the plugin angiogenesis analyser (Gilles Carpentier, ImageJ News, 5 October 2012).

\section{Axonal growth neurogenic assay}

In addition, to assess the neurogenic potential of the conditioned media from IVD cultures, an axonal growth assay using murine DRG culture, was conducted, as previously described (Neto et al., 2018). Briefly, embryonic DRGs were obtained from murine embryos (E16-18) and maintained in HBSS (Invitrogen) while being isolated under a stereoscopic magnifier. Then they were seeded into the lower wells of a $\mu$-Slide Angiogenesis plate (\#81506, Ibidi) where fibrin hydrogels were formed by a ratio of 
$1: 1$ of plasminogen-free fibrinogen solution (pooled from human plasma) to a $\mathrm{CaCl}_{2}$-containing thrombin solution. The fibrin gel was left to polymerise for $10 \mathrm{~min}$ at $37^{\circ} \mathrm{C}$ prior to the addition of the neurobasal culture medium (supplemented with $2 \%$ B-27 serumfree supplement (B-27, Invitrogen), $60 \mu \mathrm{mol} / \mathrm{L}$ FDU (Sigma-Aldrich), $25 \mathrm{mmol} / \mathrm{L}$ glucose (Sigma-Aldrich), $1 \mathrm{mmol} / \mathrm{L}$ pyruvate (Sigma-Aldrich), $50 \mathrm{ng} / \mathrm{mL}$ NGF (Merck Millipore Calbiochem ${ }^{\mathrm{TM}}$, Darmstadt, Germany), 2 mmol/L glutamine (BioWittacker, Lonza, Basel, Switzerland) and $1 \% \mathrm{P} / \mathrm{S}$ ). The DRG explant cultures were left undisturbed for $24 \mathrm{~h}$, after which the neurobasal medium was replaced by the conditioned medium collected from the $48 \mathrm{~h}$ IVD culture in each of the different conditions. Controls with neurobasal medium supplemented with NGF, MSCsec or IVD basal medium alone were performed. Axonal growth was quantified after $72 \mathrm{~h}$. DRG samples were fixed in $2 \%$ PFA at room temperature for $10 \mathrm{~min}$, followed by 10 min in $4 \%$ PFA with $4 \%$ sucrose at $37^{\circ} \mathrm{C}$. Samples were then permeabilised by incubation with $0.25 \%$ Triton X-100 for $30 \mathrm{~min}$ at room temperature, followed by blocking in $5 \%$ normal goat serum (Invitrogen) and $5 \%$ FBS, at room temperature, for $1 \mathrm{~h}$. Immunofluorescence staining was performed by incubation with the primary antibody antimouse $\beta$ III-tubulin (1 : 2000, \#G7121, 5G8, Promega), overnight at $4{ }^{\circ} \mathrm{C}$, followed by a $1 \mathrm{~h}$ incubation with the Alexafluor 488-conjugated secondary antibody (Invitrogen) at room temperature. Images were captured with an IN cell analyser 2000 and analysed with IN Cell Investigator software (GE Healthcare). Areas were automatically computed, and the outgrowth area quantified as previously reported (Neto et al., 2017).

\section{Statistical analysis}

Results are presented in box and whisker plots, as median IQR. Since the data from this work did not pass the normality test ( $\mathrm{D}^{\prime}$ Agostine and Pearson normality test), nonparametric tests were applied. When more than two groups were compared either unpaired Kruskal-Wallis test or paired Wilcoxon test, with Dunn multiple comparison test as posthoc, were used. When only two groups were compared, statistical analysis was performed using nonparametric test Mann-Whitney. A confidence level of at least $95 \%(p<0.05)$ was set. Graph Pad Prism v6.01 software was used for the analysis.

\section{Results}

Pre-conditioning of MSCs in a hypoxic and proinflammatory microenvironment promotes a proinflammatory profile

Pre-conditioning of MSCs in the presence of different oxygen levels (6\% and $21 \%$ ) and in the presence/ absence of the pro-inflammatory cytokine IL-1 $\beta$ was tested (Fig. 1a). These conditions were selected based on the IVD microenvironment cues that seemed to promote an immunomodulatory activity of MSCs, as previously demonstrated (Teixeira et al., 2018). MSCs remained highly viable and metabolically active in all the conditions tested (Fig. 1b) and their identity (based on positive expression of cell surface markers CD105, CD90 and CD73), as defined by the International Society for Cellular Therapy remained unaltered (Fig. 1c). The authors have previously demonstrated that the degenerative/proinflammatory IVD microenvironment promoted the secretion of catabolic/pro-inflammatory cytokines (IL-6, IL-8, RANTES, PGE, MCP-1) by MSCs (Teixeira et al., 2018). In the current study, it was confirmed that IL-1 $\beta$, but not hypoxia $\left(6 \% \mathrm{O}_{2}\right)$, significantly ${ }^{*}$, $p<0.05)$ increased the secretion of these cytokines by MSCs (Fig. 2a). However, because hypoxia is an intrinsic component of the degenerative IVD microenvironment and may impact aspects not explored, it was decided to maintain its use as a preconditioning factor. Thus, from this point onwards, only secretome produced under hypoxia and IL-1 $\beta(\mathrm{H}+\mathrm{IL}-1 \beta)$ was used and termed MSCsec. A wider molecular analysis of this MSCsec, using a cytokine array of 80 molecules, was performed (Fig. $2 b)$. The results revealed that this secretome obtained upon MSCs pre-conditioning with IL-1 $\beta$ is enriched in IL-6, RANTES, MCP-1, IL-1 $\beta$, TIMP-2, IL-8, GRO $\alpha / \beta / \gamma$, Leptin, MIP-3 $\alpha$ and CXCL1. By DAVID Functional Annotation Tool Software, the main signalling pathways triggered by these proteins were assessed (Fig. 2c). The most significantly enriched protein clusters relative to this array were involved in TNF signalling pathway, Neutrophil chemotaxis positive regulation, Inflammation, NOD-like receptor signalling pathway and Cellular response to FGF.

\section{Secretome of MSCs preconditioned with IL-1 $\beta$ modulates the inflammatory profile and ECM synthesis of the degenerated IVD}

MSCsec was used to treat IVD organ cultures in pro-inflammatory/degenerative conditions. Analysis of disc cell viability using PI/Annexin V staining showed no significant differences in cell death or apoptosis across all the experimental conditions (Fig. $3 \mathbf{b})$. Gene expression levels of the catabolic markers, bIL-6 and bIL-8, upregulated in the degenerative/ pro-inflammatory IVD model, as demonstrated previously (Teixeira et al., 2016), were significantly down-regulated $\left({ }^{*} p<0.05\right)$ in the presence of MSCsec, reaching levels similar to the control IVDs (Fig. 3c.1,c.2). Furthermore, the role of MSCsec on IVD ECM remodelling was explored (Fig. 3c.3-c.9). After $48 \mathrm{~h}$, a downregulation of gene expression levels of the IVD matrix components, $b C O L 2$ and $b A C A N$, and an increase in matrix-degrading enzymes, $b M M P 1$ and $b M M P 3$, was observed in the degenerative IVD model, compared with the nonstimulated discs, as previously reported (Teixeira et al., 2016). A slight decrease in the expression levels of 
MMPs inhibitor, $b$ TIMP2, was also observed, while no significant differences were observed in bTIMP1 and $b A D A M T S 5$ ( $b A D A M T S 4$ was also analysed but was expressed at very low levels, data not shown). At the same time point, MSCsec treatment significantly down-regulated gene expression of $b M M P 1$ and $b A C A N\left({ }^{*} p<0,05\right)$, while up-regulating $b M M P 3$ (1.78-fold increase) relative to the pro-inflammatory/ degenerative IVD. In addition, MSCsec increased the expression of $b T I M P 2$ in the degenerative IVD (1.49-fold increase, $p<0.01$ ). To evaluate whether these alterations reflected alterations at the protein level, the IVDs explants were analysed at a later time point, $14 \mathrm{~d}$ post-treatment (Fig. $4 \mathbf{b}, \mathbf{c}$ ). All the pro-inflammatory/degenerative IVD organ cultures presented loss of sGAG, when compared with the control, an effect that could not be reversed by the presence of MSCsec (Fig. 4c). This sGAGs loss with time in bovine IVD explants, even without inflammatory stimuli, had already been reported (Teixeira et al., 2016). At tissue level, COL1 and COL2 did not present significant alterations. Yet, ACAN levels, that were decreased on the pro-inflammatory/ degenerative IVD, were significantly increased upon MSCsec treatment $\left({ }^{*} p<0.05\right)$ (Fig. 4c).

\section{Predicted MSCsec action mechanisms in pro- inflammatory/degenerative IVD organ culture are predominantly related to the inflammatory response}

To unravel the main components of the MSCsec responsible for the observed effects in the degenerative IVD, the conditioned medium from the pro-inflammatory/degenerative IVDs organ cultures after treatment with MSCsec was screened for its protein content. An antibody membrane array was used and results compared with those from the pro-inflammatory/degenerative IVDs alone. The molecules most differently expressed (up-regulation $>5$ and down-regulation $<-5$ ) (Fig. $5 a)$, were analysed using the Functional Annotation Clustering Tool from the DAVID Database (Fig. $5 b)$. By analysis of the molecules upregulated in the MSCsec co-culture (TIMP-2, CXCL1, GRO $\alpha / \beta / \gamma$, Leptin, MCP-1, MCP-3, MIP-3 $\alpha$, IL-8, IBFBP-2, IL6, GCP-2, IGFBP-1) with the DAVID Functional Clustering Tool, a significantly enriched cluster was found that included terms implicated in neutrophil chemotaxis, NOD-like receptor signalling pathway and TNF signalling pathways, among others. In parallel, a significative downregulation of molecules was found in IVD upon MSCsec treatment (IGF-1, Eotaxin 3, FGF-9, SDF-1 $\alpha$, TNF $\alpha$, MCP-2, Eotaxin-1, Eotaxin-2, PARC, MIG, TNF $\beta$, IFN $\gamma$, MIP-1 $\delta$, IL-5, IL-16, TGF $\beta 1$, IL-4, IL-10, IGFBP-4, IGFBP-3, NT-4) (Fig. 5a). These were grouped in silico in significantly enriched clusters associated with gene ontology pathways involved with inflammation. Specifically, a subgroup of 5 molecules (IFN- $\gamma$, IL-10, IL-4, IL-5 and TNF- $\alpha$ ) was related with the $\mathrm{T}$ cell receptor signalling pathway. The presence of $\mathrm{T}$ lymphocytes in degenerated IVD has been described, but their role remains to be highlighted (Geiss et al., 2014; Kanerva et al., 1997).

\section{MSCsec treatment does not increase angiogenic/ neurogenic potential of inflammatory/ degenerative IVDs}

The angiogenic and neurogenic potential of degenerated IVDs treated with MSCsec were evaluated, using pre-established in vitro models. IVD basal medium with IL-1 $\beta$ showed a trend to inhibit angiogenesis, although the results were not statistically significant (Fig. 6a). Neither IVD conditioned medium, with/without the inflammatory stimuli, nor treated with MSCsec, promoted angiogenesis. This suggested that MSCsec could be a safe approach concerning new vessel formation, as ingrowth of blood vessels has been established as a step in the degenerative state of the physiologically avascular IVD (Ito and Creemers, 2013). Regarding neurogenesis, the results showed that the IVD medium+IL-1 $\beta$ had a tendency to promote a slight axonal growth, meaning it has neurogenic properties even when compared to the neurogenic NGFsupplemented medium (1.34-fold increase) (Fig. 6b). Nevertheless, IVD-conditioned medium, either in basal or pro-inflammatory conditions, did not stimulate axonal outgrowth. The results obtained suggest that MSCsec could be a safe approach concerning neurogenesis, as invasion by nerves has been established as a step of the degenerative state in the physiologically non-innervated IVD (Ito and Creemers, 2013).

\section{Discussion}

MSCsec has been explored for several disorders (Ferreira et al., 2018), including articular inflammatory diseases such as osteoarthritis (Mancuso et al., 2019) that resembles the IVD degenerative process (Rustenburg et al., 2018). In those studies, MSCsec was capable of protecting chondrocytes from apoptosis, inhibiting MMP activity, inducing differentiation of chondrogenic progenitors and modulating the inflammatory response, including the expression of fibrotic markers (Mancuso et al., 2019). MSCsec has also been reported to inhibit apoptosis/senescence in NP cells (Cheng et al., 2018; Qi et al., 2019), restore stemness and increase differentiation potential of degenerative IVD cells (Zeng et al., 2020), as well as increasing matrix production by these cells (Qi et al., 2019). Nevertheless, a microenvironment characterised by a high concentration of molecules with pro-inflammatory characteristics also plays a crucial role in IVD degeneration. In fact, this model replicates a catabolic environment in the disc. Yet, with the increase in levels of cytokines with pro-inflammatory roles, a pro-inflammatory microenvironment is established in the degenerative IVD (Teixeira et al., 2016). This has further ramifications 
a.1

Molecular profile after M SC sec treatment

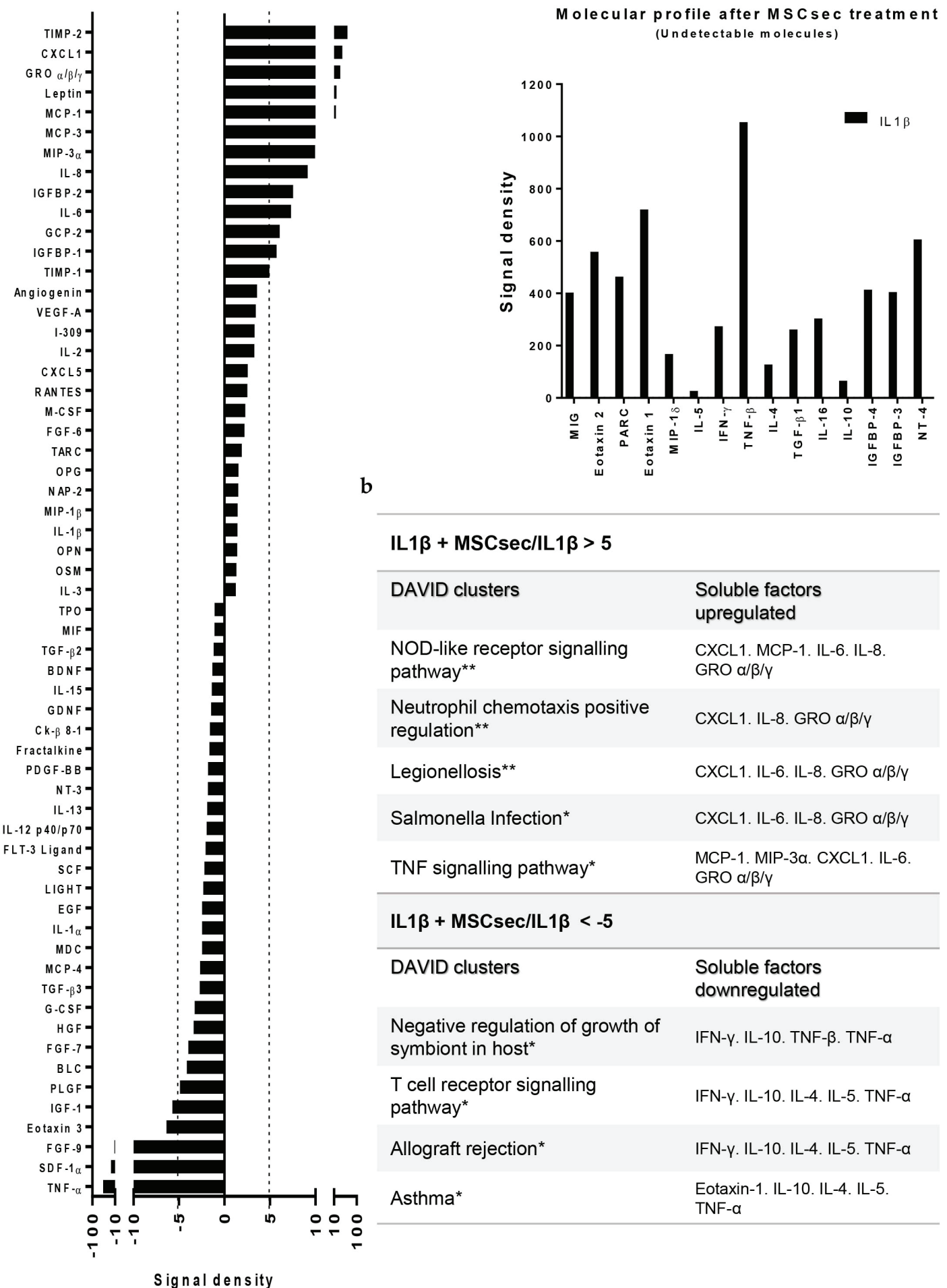

a.2 
considering the recent reports showing the presence of immune-like cells in the intact intervertebral disc (Kawakubo et al., 2020). Therefore, in the current study, the role of MSCsec on degenerated IVDs was investigated, using an ex-vivo bovine model (Teixeira et al., 2016) that simulates events of the human IVD degeneration. As healthy human discs are of limited availability and degenerated discs removal is neither frequent nor easy, the accessibility of adequate human samples is poor. Thus, the use of animal models is critical in allowing the establishment of replicable experiments for the study of both IVD degeneration and potential regenerative therapies. However, the choice of animal model is very important considering the sharp differences observed between species, including disc dimensions, ECM composition and

a.1

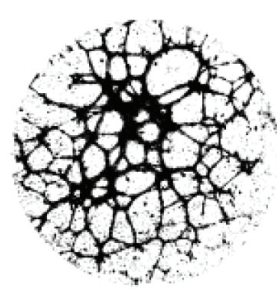

Control

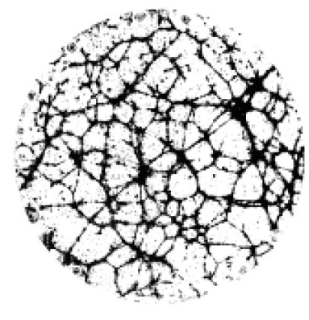

IVD_IL1 $\beta$

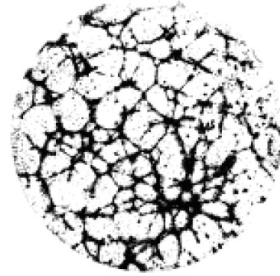

IVD_IL1 $\beta+$ MSCsec

a.2
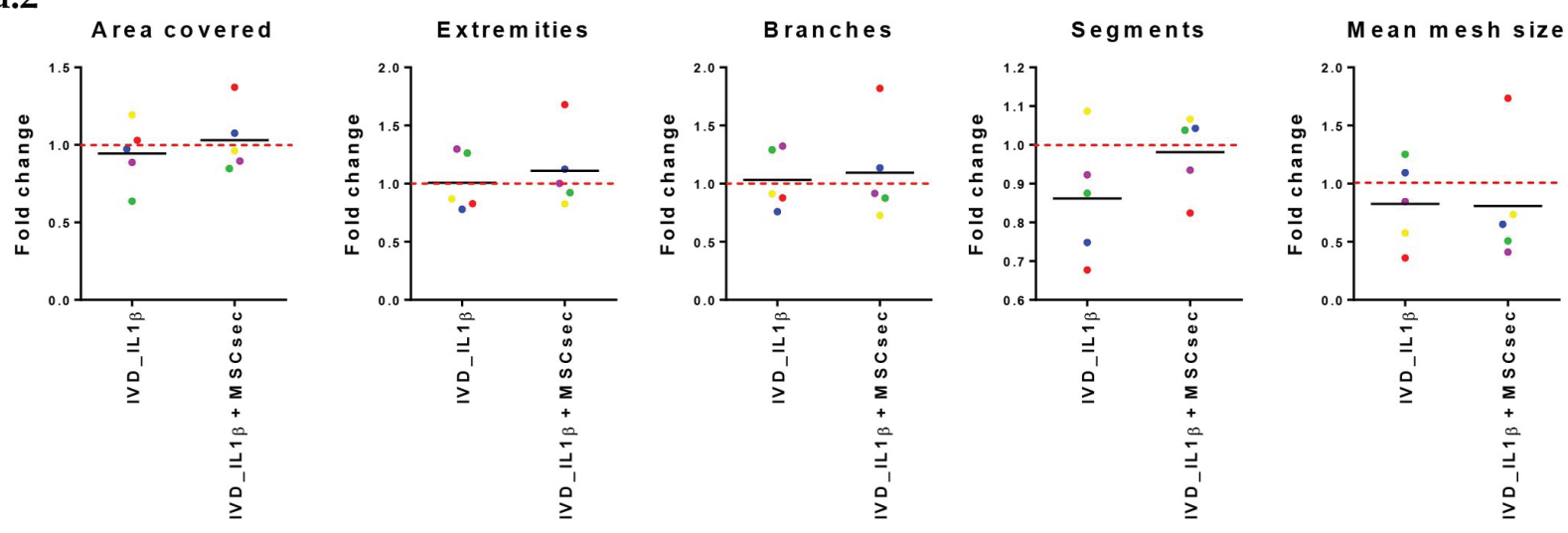

b.1
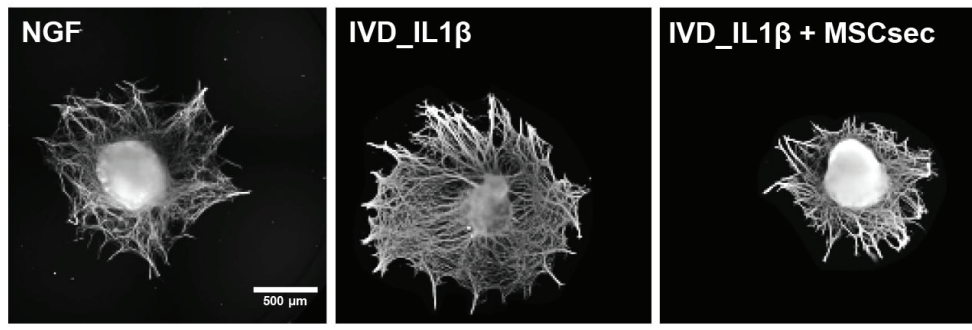

b.2

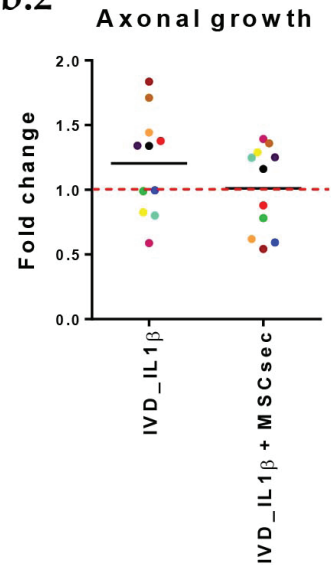

Fig. 6. Angiogenic and neurogenic potential of pro-inflammatory/degenerative bIVDs treated with MSCsec. (a) The angiogenic potential of bIVDs was evaluated by cell sprouting assay conducted on HUVECs. Representative images of the digitally processed images obtained from the vascular trees formed by HUVECs in response to the different conditions are presented, as well as plots of: percentage of cell-covered area, number of extremities, number of branches, numbers of segments and mean mesh size. All conditions were normalised relative to the pro-angiogenic control condition (dashed line $=1)(n=2-6)$. (b) The neurogenic potential of bIVDs was evaluated by DRGs culture. Representative images of DRG outgrowth after treatment (stained for $\beta$ III-tubulin) are presented and axonal outgrowth was automatically quantified (ratio of area covered by the axonal growth over the total area). All conditions were normalised relative to the neurobasal control condition containing NGF (dashed line $=1)(n=4-12)$. Results are presented as box and whiskers plots with representation of median, min and max values. 
metabolism, load applied to the discs and cellular composition. Bovine-disc dimensions are relatively similar to the human ones, especially regarding disc height, which greatly affects the tissue nutrition via diffusion from the endplates (O'Connell et al., 2007). Possibly related to this feature (Guehring et al., 2009), bovine disc cellular content also more closely resembles what is observed in the human discs (Sitte et al., 2014) with the rapid decline in notochordal cells in the NP during youth, which is not observed in most of the smaller animals (McCann and Séguin, 2016). The similar cellular content consequently translates into closely-related metabolic and catabolic responses (Miyazaki et al., 2009; Sitte et al., 2014).

MSCsec content is known to depend on the different cues present in the cells' microenvironment (Ferreira et al., 2018). The current study commenced by investigating the effect of the pro-inflammatory stimulus (IL-1 $\beta$ ) and hypoxia $\left(6 \% \mathrm{O}_{2}\right)$, two different features of the IVD microenvironment, on MSCs and their secretome. As the IVD is the largest avascular tissue in the human body, low $\mathrm{O}_{2}$ available percentage $(5-10 \%)$ is a major physiological characteristic of its microenvironment (Bartels et al., 1998). While
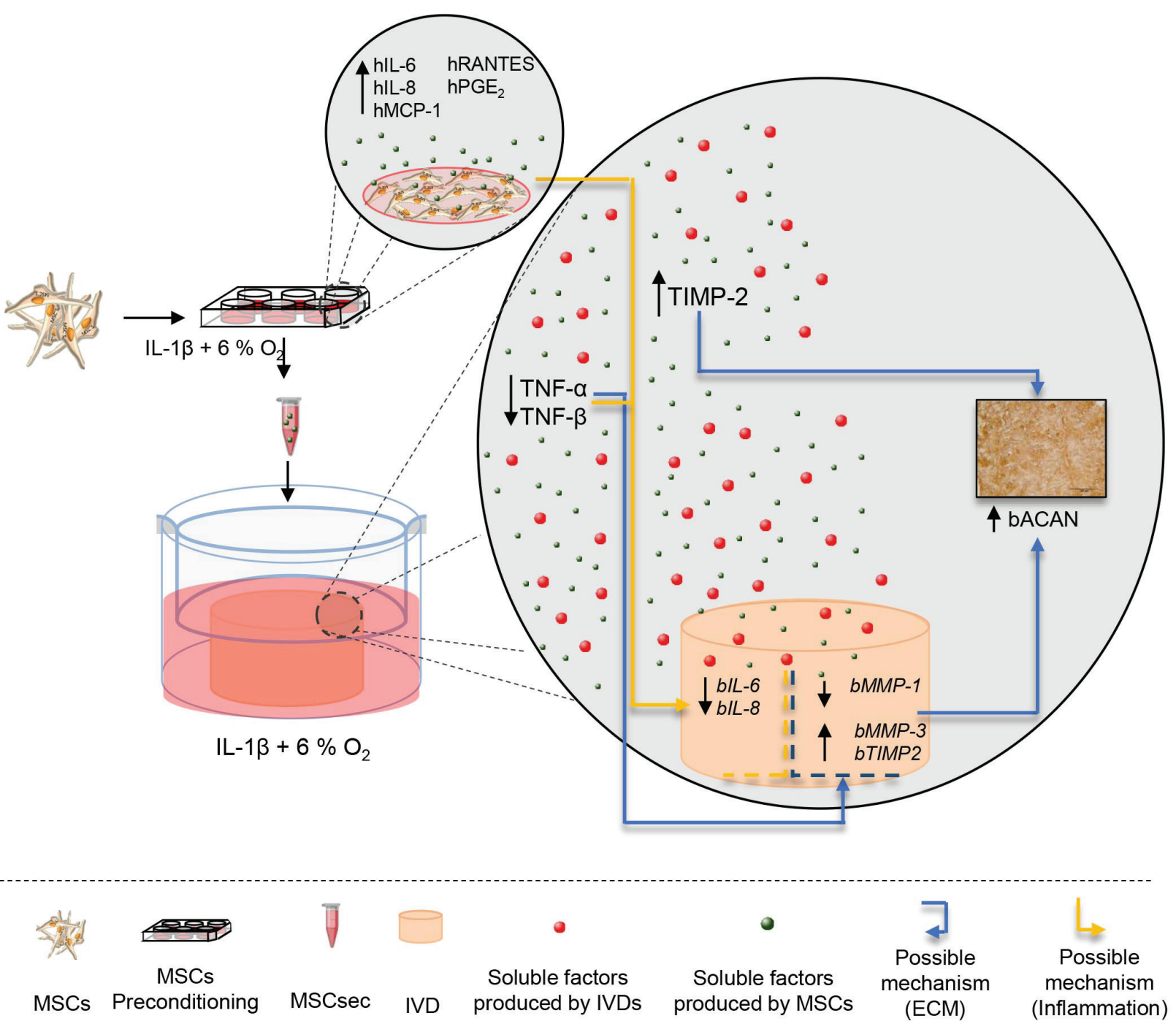

Fig. 7. Schematic representation of factors altered in response to degenerated IVD co-cultured with MSCsec. Schematic representation of the main molecular interplay between pro-inflammatory/degenerative IVDs and MSCsec from preconditioned MSCs. The key changes and proposed mechanism related with the disc inflammatory cascade are represented by yellow arrows. Blue arrows are linked to the changes observed at the disc matrix level. In response to the preconditioning, MSCs increase the production of pro-inflammatory cytokines. When treated with the MSCsec, pro-inflammatory/degenerative IVDs decrease the expression of $b I L-6$ and $b I L-8$. In consequence of this interplay, there is a dramatic decrease in the presence of TNF- $\alpha / \beta$ in the microenvironment, which can feed into this circle. Compared to the changes reported at the ECM level, pro-inflammatory/degenerative IVDs treated with MSCsec increase the expression of $b M M P-3$ and $b T I M P 2$ and decrease the expression of $b M M P-1$. Additionally, their interaction increases the concentration of TIMP-2 in the microenvironment. The decrease in TNF- $\alpha / \beta$ can be related with these effects as well. As a consequence of the changes provoked by the interplay between IVD/MSCsec, an increase in ACAN deposition in the degenerative IVD was seen. 
this hypoxic state is intensified in the degenerative state an strong reaction is established, characterised by the production of pro-inflammatory cytokines. Concerning this catabolic stimulus, IL- $1 \beta$ is the most widely reported cytokine with a pro-inflammatory role in the context of the IVD's degenerative cascade (Le Maitre et al., 2007). Treatment with IL-1 $\beta$ stimulated MSCs to secrete higher levels of pro-inflammatory cytokines, while the percentage of available oxygen did not seem to alter the production of the molecules tested. The authors have previously observed that the MSCs of a degenerative IVD significantly increase the production of these cytokines. Yet, MSCs were able to down-regulate catabolic/inflammatory markers expressed by IVD cells (Teixeira et al., 2018). Although MSCs have been shown to have an anti-inflammatory effect in response to highly inflammatory stimuli (Wang et al., 2018), their immunomodulatory response can depend on varying concentrations of the pro-inflammatory cues (Li et al., 2012).

In the current study, MSCsec treatment of IVD in degenerative conditions modulated the catabolic cascade in the degenerative disc, similarly to what was previously observed in the presence of MSCs (Teixeira et al., 2018). The mismatch between the high levels of catabolic cytokines being released into the MSCsec and the decrease in expression of those same molecules by the IVD when in the presence of the MSCsec suggests the presence of a negative feedbackbased modulatory effect. This modulatory capacity has been recently reported in a study establishing the use of conditioned medium from non-preconditioned ASCs to modulate the inflammatory response in a complex in vitro co-culture model including rat NP/ AF cells, macrophages and ASCs-CM (MiguelezRivera et al., 2018).

Although the authors have previously observed that MSCs did not promote IVD ECM remodelling under pro-catabolic conditions, the treatment with MSCsec led to a significant increase in ACAN deposition after $14 \mathrm{~d}$ of culture. It is hypothesised that the increased deposition of ACAN in the IVD could be due to a combined effect of $b M M P 1$ downregulation and up-regulation of the MMP inhibitor bTIMP2, promoted by MSCsec treatment. MSCsec is able to partially counteract the increased levels of MMPs that have been linked to disc degeneration (Goupille et al., 1998), which may then reflect an increased ACAN deposition at latter time points. Nevertheless, it was surprising that ADAMTS expression was not altered by MSCsec, since ADAMTS are reported to be more efficient at degrading ACAN than MMP3, the most efficient ACAN-degrading MMP (Durigova et al., 2011). One explanation could be that aggrecanase activity is regulated post-transcriptionally (Flannery et al., 1999). On the other hand, the effect observed in the expression levels of $b M M P 1$ and $b T I M P 2$ makes it reasonable to expect alterations to the IVDs' collagen content, an expectation not verified by the results. Degradation of collagen might be delayed due to the presence of ACAN, which has an inhibitory effect on MMPs' activity on collagen (Pratta et al., 2003), thus making it difficult to see such an effect at the same timepoint. Additionally, it is also important to address the mismatch between the increase in ACAN deposition at the same time as the sGAG content, lost in the degenerative model, is not recovered. As ACAN is composed of a core protein covalently linked to approximately 100 chains of sGAGs (specifically chondroitin sulphate and keratan sulphate) (Nap and Szleifer, 2008), an increase would be expected to be seen in the deposition of sGAG. This mismatch can be explained by several factors. The DMMB method, used to quantify sGAG content, is only able to detect sGAGs such as heparan sulphate, the third most abundant GAG in IVD and not linked to ACAN (Liu et al., 2018). At the same time, the DMMB method excludes the quantification of non-sulphated GAGs, such as hyaluronic acid, the second most abundant GAG in the IVD, commonly found linked to ACAN (Liu et al., 2018). Thus, sGAG quantification by the DMMB assay is not directly correlated with ACAN content. Moreover, increased ACAN deposition may not correlate with a higher production of its carbohydrate chains, since biosynthesis of both components have been reported to happen separately due to its high molecular complexity (Vynios, 2014). In any case, these findings are in line with recent reports showing that the presence of MSCsec leads to an increase in matrix deposition by hdDCs (Hingert et al., 2019). These authors reported an increase in the deposition of sGAG, ACAN and COL2 when hdDC-pellets were cultured in the presence of the MSCsec, which contrasts with the results of the current study where only the ACAN deposition was increased. Naturally, the sharp differences between the two models can offer some explanation for the dissimilarities found. The model used by Hingert et al. has the advantage of using human cells directly collected from degenerated tissue that can, ideally, closely mimic the cell behaviour found in vivo. However, as these cells are violently extracted from their unique microenvironment, it is not possible to absolutely guarantee the maintenance of their diseased state. Thus, a stronger therapeutic role can be expected solely because the cells would be no longer under the degenerative stimulus. This can also occur as a consequence of the optimised communication between cells from the same species or even because the culture conditions used would better expose the cells to the therapeutic stimulus. Regardless, these two reports strengthen the hypothesis that the MSCsec can have a very relevant pro-regenerative effect on the degenerative IVD, in both bovines and humans. To understand the mechanisms of a MSCsec-based therapy for IVD degeneration, the molecular content of the IVDculture supernatants was analysed. The membranebased array analysis allowed the evaluation of the dynamics of the degenerative disc microenvironment in the presence of MSCsec, although it was not 
possible to discern protein production by MSCs or IVD, due to cross-reactivity between species (human/bovine). Molecules downregulated in the culture with MSCsec (such as IFN- $\gamma$, IL-10, IL-4, IL-5, TNF- $\alpha$ ) are related to T-cell activation. Even though macrophages are the main inflammatory cells found in clinical samples of degenerated/herniated IVDs (Nakazawa et al., 2018), the presence of lymphocytes has also been reported (Shamji et al., 2010), as well as the activation of Th1 and Th17 cells associated with the degenerative process (Shamji et al., 2010) and painful symptoms (Cheng et al., 2013). These data may suggest that in an in vivo context, with a fully-competent immune system, MSCsec may have the potential to modulate other elements of the inflammatory cascade in the degenerative IVD. On the other hand, among the different functional clusters identified in the increased molecular population under each of the conditions, two were of interest in the context of IVD degeneration. In MSCsec/IVD cultures there was an enrichment in molecules related with the TNF signalling pathway, one of the main cytokines involved in the inflammatory reaction of the degenerative IVD (Risbud and Shapiro, 2014), as well as with the NOD-like receptor signalling pathway, whose activation induces IVD degeneration in humans (Krock et al., 2017). Even though several molecules related to the TNF signalling pathway were found to have increased, when MSCsec was added to the degenerative IVD, both TNF- $\alpha$ and TNF- $\beta$ levels were significantly down-regulated and undetectable, respectively. Considering this information, regardless of the strong signalling towards the activation of this pathway, it would be highly inhibited by the presence of the MSCsec that could be pivotal in explaining its influence on ACAN deposition. The TNF signalling pathway is involved with the IL-1 mediated degradation of ACAN in osteoarthritis, through the stimulation of ADAMTS (Ismail et al., 2015; Xue et al., 2013) and has been reported to increase levels of MMPs and ADAMTSs and decrease COL2 and ACAN deposition in the NP tissue (Séguin et al., 2005). So, it seems possible that a decrease in the levels of TNF- $\alpha / \beta$ molecules would lead to an inhibition of these matrix-degrading enzymes. It is worth noting that, even though both IL- $1 \beta$ and TNF- $\alpha$ were reported to stimulate MMPs, IL- $1 \beta$ is known to have a stronger effect on MMP3 (Millward-Sadler et al., 2009), which could account for the higher levels of MMP3 observed in these experiments.

IVD degeneration is known to be a complex process, involving a pro-inflammatory response, that can stimulate angiogenesis and innervation towards the degenerated IVD (Lee et al., 2011). Both MSCs and their secretome have been described as angiogenic (Tao et al., 2016) and neurogenic (Salgado et al., 2015), which can be beneficial for tissue repair/regeneration in vascularised and innervated tissues, but can impair the use of MSCsec as a therapeutic strategy for LBP. Moreover, the effect of MSCsec on ACAN deposition can have implications on the pro-neurogenic and pro- angiogenic potential of the degenerated IVD, as it has been reported that ACAN isolated from the human IVD inhibits nerve growth (Johnson et al., 2002; Johnson et al., 2004) and endothelial cell adhesion, spreading and migration (Johnson et al., 2004) in vitro. Therefore, the angiogenic and neurogenic potential of degenerated IVDs treated with MSCsec were also evaluated. The MSCsec treatment of IVD did not promote angiogenesis or axonal outgrowth, under the culture conditions used. These results were corroborated by the findings that levels of pro-angiogenic molecules (angiogenin, VEGF-A and PLGF) were not significantly up-regulated and all the neuroprotective molecules tested (BDNF, GDNF, NT3, FGF-7 and NT-4) were decreased in MSCsec-treated IVD supernatants. Even though both IL-1 $\beta$ and MSCsec have been shown to stimulate angiogenesis (Fan et al., 2004; Rosell et al., 2009), the observed upregulation of pro-angiogenic factors (Fan et al., 2004) could not translate into a full functional effect. Additionally, functional assays performed on murine spleen-derived endothelial progenitor cells may have dramatically different outcomes from those using HUVECs, solely based on cell origin (Rosell et al., 2009). However, the pro-angiogenic effect of MSCsec on HUVECs was tested using the secretome of murine MSCs without any preconditioning (Estrada et al., 2009), two factors that can deeply influence the cellular response to the stimulus. Identically, despite reports showing that both the IVD and IL-1 $\beta$ inhibit axonal outgrowth from DRGs (Larsson et al., 2011; Larsson et al., 2005), the results of the current study suggest an enhancement, by both factors, of axonal outgrowth, at the level of the NGFcontaining neurobasal medium. These differences could easily be attributed to interspecies differences because both previous studies (Larsson et al., 2011; Larsson et al., 2005) used DRGs and IVDs from the same species, unlike the assays described here. The results reported here offer early evidence that, due to the lack of stimulatory effects, the use of MSCsec as a treatment for the degenerative IVD could be safe regarding potential angiogenesis/neurogenesis related side effects.

This study was conducted using the secretome obtained with MSCs concentration, culture medium, and culture conditions similar to what has been previously used and demonstrated to have an immunomodulatory role in degenerated IVD (Teixeira et al., 2018). Nevertheless, there were limitations with regard to addressing the dose-, donor- or mediumdependent action of MSCsec. Preliminary studies by the authors' group have shown that MSCsec obtained with distinct cell concentrations $\left(2 \times 10^{5}\right.$ and $1 \times 10^{6} \mathrm{MSC} / 5 \mathrm{~mL}$ of medium) revealed similar IL-6, IL-8, PGE 2 and MCP-1 concentrations and induced similar down-regulation of $b I L-6$ and $b I L-8$ in degenerated IVD (data not shown). Furthermore, this study was conducted using different MSCs donors thus accounting for donor variability, an important aspect for clinical translation of the results obtained. 
Despite the promising results, a high-throughput study should be conducted to optimise the conditions used to obtain a MSCsec-based product with the most potent therapeutic properties for degenerated IVD. In particular, the production of MSCsec in serum-deprived conditions and the study of specific fractions of MSCsec or the specific contribution of the secreted vesicles should also be addressed. Additionally, attention should be given to the delivery mechanism envisioned for the MSCsec in the clinical context of the disease. Its molecular richness, which so critically contributes to the therapeutic potential reported, can also carry some risks. The concern that the MSCsec can have a chemoattractant effect on circulatory immune cells is legitimate, more so when its administration may include the creation of a micro-injury in the AF. Therefore, the study of applying MSCsec treatment to degenerated IVDs should be addressed in more complex models, that include the immune system, such as organotypic cocultures with monocytes/macrophages as developed in the authors' group (Silva et al., 2019) or even more complex models, using organs-on-a-chip or in vivo models.

\section{Conclusions}

MSCsec, produced in response to preconditioning with IL-1 $\beta$ and $6 \% \mathrm{O}_{2}$, presents a modulatory role on the pro-inflammatory environment of the degenerative IVD and promotes ACAN deposition in the IVD. The results reported here hint at the hypothesis that these effects may be mediated by an inhibition of the TNF signalling pathway and an interplay between TIMP2 and MMP1/3 that contributes to the promotion of ACAN deposition. Importantly, these results demonstrate the potential use of MSCsec in the context of IVD degeneration and LBP, while taking the first steps into exploring the safety of the approach.

\section{Acknowledgements}

\section{Competing interests}

AMS is currently an employee of AstraZeneca R\&D, Gothenburg, Sweden.

\section{Funding}

This work was financed by EUROSPINE TRF (2017_05) through the project "Disc degeneration-, immune- and neuro-modulation" and also by European Union funds, N2020 through the project "Projetos Estruturados de I\&D\&I - Norte-01-0145FEDER-000012, Portugal 2020 - FEDER". The authors also acknowledge FCT - Fundação para a Ciência e a Tecnologia, in the framework of the PhD grant of JRF (PD/BI/128357/2017).

\section{Authors' contributions}

JRF and RMG contributed to the study conception and design. JRF, GQT, EN, CR-M, AMS, SB, AM and CLP contributed to the acquisition of data. JRF, RMG, GQT, EN, JC, MB and ML contributed to the analysis and interpretation of data. JRF and RMG drafted the article. MB, ML and RMG provided the funding for the experiments. All authors have critically revised the article for important intellectual content, and all authors approved the final submitted version.

The authors acknowledge the support of the i3S Scientific Platform BioSciences Screening, member of the PPBI (PPBI-POCI-01-0145-FEDER-022122) and PT-OPENSCREEN.

\section{References}

Almeida CR, Vasconcelos DP, Goncalves RM, Barbosa MA (2012) Enhanced mesenchymal stromal cell recruitment via natural killer cells by incorporation of inflammatory signals in biomaterials. J R Soc Interface 9: 261-271.

Bartels EM, Fairbank JC, Winlove CP, Urban JP (1998) Oxygen and lactate concentrations measured in vivo in the intervertebral discs of patients with scoliosis and back pain. Spine (Phila Pa 1976) 23: 1-7.

Bidarra SJ, Barrias CC, Barbosa MA, Soares R, Granja PL (2010) Immobilization of human mesenchymal stem cells within RGD-grafted alginate microspheres and assessment of their angiogenic potential. Biomacromolecules 11: 1956-1964.

Binch ALA, Cole AA, Breakwell LM, Michael ALR, Chiverton N, Creemers LB, Cross AK, Le Maitre CL (2015) Nerves are more abundant than blood vessels in the degenerate human intervertebral disc. Arthritis Res Ther 17: 370-370.

Caldeira J, Santa C, Osório H, Molinos M, Manadas B, Gonçalves R, Barbosa M (2017) Matrisome profiling during intervertebral disc development and ageing. Sci Rep 7: 11629. DOI: 10.1038/s41598-017-11960-0.

Chen S, Zhao L, Deng X, Shi D, Wu F, Liang H, Huang D, Shao Z (2017) Mesenchymal stem cells protect nucleus pulposus cells from compressioninduced apoptosis by inhibiting the mitochondrial pathway. Stem Cells Int 2017: 9843120. DOI: 10.1155/2017/9843120.

Cheng L, Fan W, Liu B, Wang X, Nie L (2013) Th17 lymphocyte levels are higher in patients with ruptured than non-ruptured lumbar discs, and are correlated with pain intensity. Injury 44: 1805-1810.

Cheng X, Zhang G, Zhang L, Hu Y, Zhang K, Sun X, Zhao C, Li H, Li YM, Zhao J (2018) Mesenchymal stem cells deliver exogenous miR-21 via exosomes to inhibit nucleus pulposus cell apoptosis and reduce intervertebral disc degeneration. J Cell Mol Med 22: 261-276.

Cunha C, Almeida CR, Almeida MI, Silva AM, Molinos M, Lamas S, Pereira CL, Teixeira GQ, 
Monteiro AT, Santos SG, Gonçalves RM, Barbosa MA (2017) Systemic delivery of bone marrow mesenchymal stem cells for in situ intervertebral disc regeneration. Stem Cells Transl Med 6: 1029-1039.

Cunningham CJ, Redondo-Castro E, Allan SM (2018) The therapeutic potential of the mesenchymal stem cell secretome in ischaemic stroke. J Cereb Blood Flow Metab 38: 1276-1292.

DePalma MJ, Ketchum JM, Saullo T (2011) What is the source of chronic low back pain and does age play a role? Pain Med 12: 224-233.

Dominici M, Le Blanc K, Mueller I, SlaperCortenbach I, Marini F, Krause D, Deans R, Keating A, Prockop D, Horwitz E (2006) Minimal criteria for defining multipotent mesenchymal stromal cells. The International Society for Cellular Therapy position statement. Cytotherapy 8: 315-317.

Durigova M, Nagase H, Mort JS, Roughley PJ (2011) MMPs are less efficient than ADAMTS5 in cleaving aggrecan core protein. Matrix Biol 30: 145153.

Estrada R, Li N, Sarojini H, An J, Lee M-J, Wang E (2009) Secretome from mesenchymal stem cells induces angiogenesis via Cyr61. J Cell Physiol 219: 563-571.

Fan F, Stoeltzing O, Liu W, McCarty MF, Jung YD, Reinmuth N, Ellis LM (2004) Interleukin-1beta regulates angiopoietin-1 expression in human endothelial cells. Cancer Res 64: 3186-3190.

Ferreira JR, Teixeira GQ, Santos SG, Barbosa MA, Almeida-Porada G, Goncalves RM (2018) Mesenchymal stromal cell secretome: influencing therapeutic potential by cellular preconditioning. Front Immunol 9: 2837. DOI: 10.3389/ fimmu.2018.02837.

Flannery CR, Little CB, Hughes CE, Caterson B (1999) Expression of ADAMTS homologues in articular cartilage. Biochem Biophys Res Commun 260: 318-322.

Geiss A, Sobottke R, Delank KS, Eysel P (2014) Macrophages do not represent the main cell type in sequestrated and extruded intervertebral discs: evidence for their involvement in disc resorption, rather than initiation of an immune response. Global Spine J 4: s-0034-1376618. DOI: 10.1055/s-00341376618.

Goupille P, Jayson MI, Valat JP, Freemont AJ (1998) Matrix metalloproteinases: the clue to intervertebral disc degeneration? Spine (Phila Pa 1976) 23: 1612 1626.

Gregori J, Villarreal L, Sánchez A, Baselga J, Villanueva J (2013) An effect size filter improves the reproducibility in spectral counting-based comparative proteomics. J Proteomics 95: 55-65.

Guehring T, Wilde G, Sumner M, Grünhagen T, Karney GB, Tirlapur UK, Urban JPG (2009) Notochordal intervertebral disc cells: sensitivity to nutrient deprivation. Arthritis Rheum 60: 1026-1034.

Harrop JS, Youssef JA, Maltenfort M, Vorwald P, Jabbour P, Bono CM, Goldfarb N, Vaccaro AR, Hilibrand AS (2008) Lumbar adjacent segment degeneration and disease after arthrodesis and total disc arthroplasty. Spine (Phila Pa 1976) 33: 1701-1707.

Hingert D, Nawilaijaroen P, Aldridge J, Baranto A, Brisby H (2019) Investigation of the effect of secreted factors from mesenchymal stem cells on disc cells from degenerated discs. Cells Tissues Organs 208: 76-88.

Hiyama A, Mochida J, Iwashina T, Omi H, Watanabe T, Serigano K, Tamura F, Sakai D (2008) Transplantation of mesenchymal stem cells in a canine disc degeneration model. J Orthop Res 26: 589-600.

Huang DW, Sherman BT, Tan Q, Collins JR, Alvord WG, Roayaei J, Stephens R, Baseler MW, Lane HC, Lempicki RA (2007) The DAVID Gene Functional Classification Tool: a novel biological module-centric algorithm to functionally analyze large gene lists. Genome Biol 8: R183. DOI: 10.1186/gb-2007-8-9-r183.

Ismail HM, Yamamoto K, Vincent TL, Nagase H, Troeberg L, Saklatvala J (2015) Interleukin-1 acts via the JNK-2 signaling pathway to induce aggrecan degradation by human chondrocytes. Arthritis Rheumatol 67: 1826-1836.

Ito K, Creemers L (2013) Mechanisms of intervertebral disk degeneration/injury and pain: a review. Global Spine J 3: 145-152.

James SL, Abate D, Abate KH, Abay SM, Abbafati C, Abbasi N, Abbastabar H, Abd-Allah F, Abdela J, Abdelalim A, Abdollahpour I, Abdulkader RS, Abebe Z, Abera SF, Abil OZ, Abraha HN, Abu-Raddad LJ, Abu-Rmeileh NME, Accrombessi MMK, Acharya D, Acharya P, Ackerman IN, Adamu AA, Adebayo OM, Adekanmbi V, Adetokunboh OO, Adib MG, Adsuar JC, Afanvi KA, Afarideh M, Afshin A, Agarwal G, Agesa KM, Aggarwal R, Aghayan SA, Agrawal S, Ahmadi A, Ahmadi M, Ahmadieh H, Ahmed MB, Aichour AN, Aichour I, Aichour MTE, Akinyemiju T, Akseer N, Al-Aly Z, Al-Eyadhy A, Al-Mekhlafi HM, Al-Raddadi RM, Alahdab F, Alam K, Alam T, Alashi A, Alavian SM, Alene KA, Alijanzadeh M, Alizadeh-Navaei R, Aljunid SM, Alkerwi Aa, Alla F, Allebeck P, Alouani MML, Altirkawi K, AlvisGuzman N, Amare AT, Aminde LN, Ammar W, Amoako YA, Anber NH, Andrei CL, Androudi S, Animut MD, Anjomshoa M, Ansha MG, Antonio CAT, Anwari P, Arabloo J, Arauz A, Aremu O, Ariani F, Armoon B, Ärnlöv J, Arora A, Artaman A, Aryal KK, Asayesh H, Asghar RJ, Ataro Z, Atre SR, Ausloos M, Avila-Burgos L, Avokpaho EFGA, Awasthi A, Ayala Quintanilla BP, Ayer R, Azzopardi PS, Babazadeh A, Badali H, Badawi A, Bali AG, Ballesteros KE, Ballew SH, Banach M, Banoub JAM, Banstola A, Barac A, Barboza MA, Barker-Collo SL, Bärnighausen TW, Barrero LH, Baune BT, BazarganHejazi S, Bedi N, Beghi E, Behzadifar M, Behzadifar M, Béjot Y, Belachew AB, Belay YA, Bell ML, Bello AK, Bensenor IM, Bernabe E, Bernstein RS, Beuran M, Beyranvand T, Bhala N, Bhattarai S, Bhaumik S, Bhutta ZA, Biadgo B, Bijani A, Bikbov B, Bilano V, Bililign N, Bin Sayeed MS, Bisanzio D, Blacker BF, Blyth FM, Bou-Orm IR, Boufous S, Bourne R, Brady 
OJ, Brainin M, Brant LC, Brazinova A, Breitborde NJK, Brenner $\mathrm{H}$, Briant PS, Briggs AM, Briko AN, Britton G, Brugha T, Buchbinder R, Busse R, Butt ZA, Cahuana-Hurtado L, Cano J, Cárdenas R, Carrero JJ, Carter A, Carvalho F, Castañeda-Orjuela CA, Castillo Rivas J, Castro F, Catalá-López F, Cercy KM, Cerin E, Chaiah Y, Chang AR, Chang H-Y, Chang J-C, Charlson FJ, Chattopadhyay A, Chattu VK, Chaturvedi $\mathrm{P}$, Chiang PP-C, Chin KL, Chitheer A, Choi J-YJ, Chowdhury R, Christensen H, Christopher DJ, Cicuttini FM, Ciobanu LG, Cirillo M, Claro RM, Collado-Mateo D, Cooper C, Coresh J, Cortesi PA, Cortinovis M, Costa M, Cousin E, Criqui MH, Cromwell EA, Cross M, Crump JA, Dadi AF, Dandona L, Dandona R, Dargan PI, Daryani A, Das Gupta R, Das Neves J, Dasa TT, Davey G, Davis AC, Davitoiu DV, De Courten B, De La Hoz FP, De Leo $D$, De Neve J-W, Degefa MG, Degenhardt L, Deiparine S, Dellavalle RP, Demoz GT, Deribe K, Dervenis N, Des Jarlais DC, Dessie GA, Dey S, Dharmaratne SD, Dinberu MT, Dirac MA, Djalalinia S, Doan L, Dokova K, Doku DT, Dorsey ER, Doyle KE, Driscoll TR, Dubey M, Dubljanin E, Duken EE, Duncan BB, Duraes AR, Ebrahimi H, Ebrahimpour S, Echko MM, Edvardsson D, Effiong A, Ehrlich JR, El Bcheraoui C, El Sayed Zaki M, El-Khatib Z, Elkout H, Elyazar IRF, Enayati A, Endries AY, Er B, Erskine HE, Eshrati B, Eskandarieh S, Esteghamati A, Esteghamati S, Fakhim H, Fallah Omrani V, Faramarzi M, Fareed M, Farhadi F, Farid TA, Farinha CSEs, Farioli A, Faro A, Farvid MS, Farzadfar F, Feigin VL, Fentahun N, Fereshtehnejad S-M, Fernandes E, Fernandes JC, Ferrari AJ, Feyissa GT, Filip I, Fischer F, Fitzmaurice C, Foigt NA, Foreman KJ, Fox J, Frank TD, Fukumoto T, Fullman N, Fürst T, Furtado JM, Futran ND, Gall S, Ganji M, Gankpe FG, GarciaBasteiro AL, Gardner WM, Gebre AK, Gebremedhin AT, Gebremichael TG, Gelano TF, Geleijnse JM, Genova-Maleras R, Geramo YCD, Gething PW, Gezae KE, Ghadiri K, Ghasemi Falavarjani K, GhasemiKasman M, Ghimire M, Ghosh R, Ghoshal AG, Giampaoli S, Gill PS, Gill TK, Ginawi IA, Giussani G, Gnedovskaya EV, Goldberg EM, Goli S, GómezDantés H, Gona PN, Gopalani SV, Gorman TM, Goulart AC, Goulart BNG, Grada A, Grams ME, Grosso G, Gugnani HC, Guo Y, Gupta PC, Gupta R, Gupta R, Gupta T, Gyawali B, Haagsma JA, Hachinski V, Hafezi-Nejad N, Haghparast Bidgoli H, Hagos TB, Hailu GB, Haj-Mirzaian A, Haj-Mirzaian A, Hamadeh RR, Hamidi S, Handal AJ, Hankey GJ, Hao Y, Harb HL, Harikrishnan S, Haro JM, Hasan M, Hassankhani H, Hassen HY, Havmoeller R, Hawley CN, Hay RJ, Hay SI, Hedayatizadeh-Omran A, Heibati B, Hendrie D, Henok A, Herteliu C, Heydarpour S, Hibstu DT, Hoang HT, Hoek HW, Hoffman HJ, Hole MK, Homaie Rad E, Hoogar P, Hosgood HD, Hosseini SM, Hosseinzadeh M, Hostiuc M, Hostiuc S, Hotez PJ, Hoy DG, Hsairi M, Htet AS, Hu G, Huang JJ, Huynh CK, Iburg KM, Ikeda CT, Ileanu B, Ilesanmi OS, Iqbal U, Irvani SSN, Irvine CMS, Islam SMS, Islami F, Jacobsen $\mathrm{KH}$, Jahangiry L, Jahanmehr N,
Jain SK, Jakovljevic M, Javanbakht M, Jayatilleke AU, Jeemon P, Jha RP, Jha V, Ji JS, Johnson CO, Jonas JB, Jozwiak JJ, Jungari SB, Jürisson M, Kabir Z, Kadel R, Kahsay A, Kalani R, Kanchan T, Karami M, Karami Matin B, Karch A, Karema C, Karimi N, Karimi SM, Kasaeian A, Kassa DH, Kassa GM, Kassa TD, Kassebaum NJ, Katikireddi SV, Kawakami N, Karyani AK, Keighobadi MM, Keiyoro PN, Kemmer L, Kemp GR, Kengne AP, Keren A, Khader YS, Khafaei B, Khafaie MA, Khajavi A, Khalil IA, Khan EA, Khan MS, Khan MA, Khang Y-H, Khazaei M, Khoja AT, Khosravi A, Khosravi MH, Kiadaliri AA, Kiirithio DN, Kim C-I, Kim D, Kim P, Kim Y-E, Kim YJ, Kimokoti RW, Kinfu Y, Kisa A, Kissimova-Skarbek K, Kivimäki M, Knudsen AKS, Kocarnik JM, Kochhar S, Kokubo Y, Kolola T, Kopec JA, Kosen S, Kotsakis GA, Koul PA, Koyanagi A, Kravchenko MA, Krishan K, Krohn KJ, Kuate Defo B, Kucuk Bicer B, Kumar GA, Kumar M, Kyu HH, Lad DP, Lad SD, Lafranconi A, Lalloo R, Lallukka T, Lami FH, Lansingh VC, Latifi A, Lau KM-M, Lazarus JV, Leasher JL, Ledesma JR, Lee PH, Leigh J, Leung J, Levi M, Lewycka S, Li S, Li Y, Liao Y, Liben ML, Lim L-L, Lim SS, Liu S, Lodha R, Looker KJ, Lopez AD, Lorkowski S, Lotufo PA, Low N, Lozano R, Lucas TCD, Lucchesi LR, Lunevicius R, Lyons RA, Ma S, Macarayan ERK, Mackay MT, Madotto F, Magdy Abd El Razek H, Magdy Abd El Razek M, Maghavani DP, Mahotra NB, Mai HT, Majdan M, Majdzadeh R, Majeed A, Malekzadeh R, Malta DC, Mamun AA, Manda A-L, Manguerra $\mathrm{H}$, Manhertz T, Mansournia MA, Mantovani LG, Mapoma CC, Maravilla JC, Marcenes W, Marks A, Martins-Melo FR, Martopullo I, März W, Marzan MB, Mashamba-Thompson TP, Massenburg BB, Mathur MR, Matsushita K, Maulik PK, Mazidi M, McAlinden C, McGrath JJ, McKee M, Mehndiratta MM, Mehrotra R, Mehta KM, Mehta V, Mejia-Rodriguez F, Mekonen T, Melese A, Melku M, Meltzer M, Memiah PTN, Memish ZA, Mendoza W, Mengistu DT, Mengistu G, Mensah GA, Mereta ST, Meretoja A, Meretoja TJ, Mestrovic T, Mezerji NMG, Miazgowski B, Miazgowski T, Millear AI, Miller TR, Miltz B, Mini GK, Mirarefin M, Mirrakhimov EM, Misganaw AT, Mitchell PB, Mitiku H, Moazen B, Mohajer B, Mohammad KA, Mohammadifard N, Mohammadnia-Afrouzi M, Mohammed MA, Mohammed S, Mohebi F, Moitra M, Mokdad AH, Molokhia M, Monasta L, Moodley Y, Moosazadeh M, Moradi G, Moradi-Lakeh M, Moradinazar M, Moraga P, Morawska L, Moreno Velásquez I, Morgado-Da-Costa J, Morrison SD, Moschos MM, Mousavi SM, Mruts KB, Muche AA, Muchie KF, Mueller UO, Muhammed OS, Mukhopadhyay S, Muller K, Mumford JE, Murhekar M, Musa J, Musa KI, Mustafa G, Nabhan AF, Nagata C, Naghavi M, Naheed A, Nahvijou A, Naik G, Naik N, Najafi F, Naldi L, Nam HS, Nangia V, Nansseu JR, Nascimento BR, Natarajan G, Neamati N, Negoi I, Negoi RI, Neupane S, Newton CRJ, Ngunjiri JW, Nguyen AQ, Nguyen HT, Nguyen HLT, Nguyen HT, Nguyen LH, Nguyen M, Nguyen NB, Nguyen SH, Nichols E, 
Ningrum DNA, Nixon MR, Nolutshungu N, Nomura S, Norheim OF, Noroozi M, Norrving B, Noubiap JJ, Nouri HR, Nourollahpour Shiadeh M, Nowroozi MR, Nsoesie EO, Nyasulu PS, Odell CM, Ofori-Asenso R, Ogbo FA, Oh I-H, Oladimeji O, Olagunju AT, Olagunju TO, Olivares PR, Olsen HE, Olusanya BO, Ong KL, Ong SK, Oren E, Ortiz A, Ota E, Otstavnov SS, Øverland S, Owolabi MO, P A M, Pacella R, Pakpour AH, Pana A, Panda-Jonas S, Parisi A, Park E-K, Parry CDH, Patel S, Pati S, Patil ST, Patle A, Patton GC, Paturi VR, Paulson KR, Pearce N, Pereira DM, Perico N, Pesudovs K, Pham HQ, Phillips MR, Pigott DM, Pillay JD, Piradov MA, Pirsaheb M, Pishgar F, Plana-Ripoll O, Plass D, Polinder S, Popova S, Postma MJ, Pourshams A, Poustchi H, Prabhakaran D, Prakash S, Prakash V, Purcell CA, Purwar MB, Qorbani M, Quistberg DA, Radfar A, Rafay A, Rafiei A, Rahim F, Rahimi K, Rahimi-Movaghar A, RahimiMovaghar V, Rahman M, Rahman MHu, Rahman MA, Rahman SU, Rai RK, Rajati F, Ram U, Ranjan P, Ranta A, Rao PC, Rawaf DL, Rawaf S, Reddy KS, Reiner RC, Reinig N, Reitsma MB, Remuzzi G, Renzaho AMN, Resnikoff S, Rezaei S, Rezai MS, Ribeiro ALP, Robinson SR, Roever L, Ronfani L, Roshandel G, Rostami A, Roth GA, Roy A, Rubagotti E, Sachdev PS, Sadat N, Saddik B, Sadeghi E, Saeedi Moghaddam S, Safari H, Safari Y, Safari-Faramani R, Safdarian M, Safi S, Safiri S, Sagar R, Sahebkar A, Sahraian MA, Sajadi HS, Salam N, Salama JS, Salamati P, Saleem K, Saleem Z, Salimi Y, Salomon JA, Salvi SS, Salz I, Samy AM, Sanabria J, Sang Y, Santomauro DF, Santos IS, Santos JV, Santric Milicevic MM, Sao Jose BP, Sardana M, Sarker AR, Sarrafzadegan N, Sartorius B, Sarvi S, Sathian B, Satpathy M, Sawant AR, Sawhney M, Saxena S, Saylan M, Schaeffner E, Schmidt MI, Schneider IJC, Schöttker B, Schwebel DC, Schwendicke F, Scott JG, Sekerija M, Sepanlou SG, Serván-Mori E, Seyedmousavi S, Shabaninejad H, Shafieesabet A, Shahbazi M, Shaheen AA, Shaikh MA, Shams-Beyranvand M, Shamsi M, Shamsizadeh M, Sharafi H, Sharafi K, Sharif M, Sharif-Alhoseini M, Sharma M, Sharma R, She J, Sheikh A, Shi P, Shibuya K, Shigematsu M, Shiri R, Shirkoohi R, Shishani K, Shiue I, Shokraneh F, Shoman H, Shrime MG, Si S, Siabani S, Siddiqi TJ, Sigfusdottir ID, Sigurvinsdottir R, Silva JP, Silveira DGA, Singam NSV, Singh JA, Singh NP, Singh V, Sinha DN, Skiadaresi E, Slepak ELN, Sliwa K, Smith DL, Smith M, Soares Filho AM, Sobaih BH, Sobhani S, Sobngwi E, Soneji SS, Soofi M, Soosaraei M, Sorensen RJD, Soriano JB, Soyiri IN, Sposato LA, Sreeramareddy CT, Srinivasan V, Stanaway JD, Stein DJ, Steiner C, Steiner TJ, Stokes MA, Stovner LJ, Subart ML, Sudaryanto A, Sufiyan MaB, Sunguya BF, Sur PJ, Sutradhar I, Sykes BL, Sylte DO, Tabarés-Seisdedos R, Tadakamadla SK, Tadesse BT, Tandon N, Tassew SG, Tavakkoli M, Taveira N, Taylor HR, TehraniBanihashemi A, Tekalign TG, Tekelemedhin SW, Tekle MG, Temesgen H, Temsah M-H, Temsah O, Terkawi AS, Teweldemedhin M, Thankappan KR,
Thomas N, Tilahun B, To QG, Tonelli M, ToporMadry R, Topouzis F, Torre AE, Tortajada-Girbés M, Touvier M, Tovani-Palone MR, Towbin JA, Tran BX, Tran KB, Troeger CE, Truelsen TC, Tsilimbaris MK, Tsoi D, Tudor Car L, Tuzcu EM, Ukwaja KN, Ullah I, Undurraga EA, Unutzer J, Updike RL, Usman MS, Uthman OA, Vaduganathan M, Vaezi A, Valdez PR, Varughese S, Vasankari TJ, Venketasubramanian N, Villafaina S, Violante FS, Vladimirov SK, Vlassov V, Vollset SE, Vosoughi K, Vujcic IS, Wagnew FS, Waheed Y, Waller SG, Wang Y, Wang Y-P, Weiderpass E, Weintraub RG, Weiss DJ, Weldegebreal F, Weldegwergs KG, Werdecker A, West TE, Whiteford HA, Widecka J, Wijeratne T, Wilner LB, Wilson S, Winkler AS, Wiyeh AB, Wiysonge CS, Wolfe CDA, Woolf AD, Wu S, Wu Y-C, Wyper GMA, Xavier D, Xu G, Yadgir S, Yadollahpour A, Yahyazadeh Jabbari SH, Yamada T, Yan LL, Yano Y, Yaseri M, Yasin YJ, Yeshaneh A, Yimer EM, Yip P, Yisma E, Yonemoto N, Yoon S-J, Yotebieng M, Younis MZ, Yousefifard M, Yu C, Zadnik V, Zaidi Z, Zaman SB, Zamani M, Zare Z, Zeleke AJ, Zenebe ZM, Zhang K, Zhao Z, Zhou M, Zodpey S, Zucker I, Vos T, Murray CJL (2018) Global, regional, and national incidence, prevalence, and years lived with disability for 354 diseases and injuries for 195 countries and territories, 1990-2017: a systematic analysis for the Global Burden of Disease Study 2017. Lancet 392: 1789-1858.

Johnson WE, Caterson B, Eisenstein SM, Hynds DL, Snow DM, Roberts S (2002) Human intervertebral disc aggrecan inhibits nerve growth in vitro. Arthritis Rheum 46: 2658-2664.

Johnson WEB, Caterson B, Eisenstein SM, Snow DM, Roberts S (2004) The effects of human intervertebral disc aggrecan on neuronal and endothelial cell growth. Int J Exp Pathol 85: A66. DOI: 10.1111/j.0959-9673.2004.390ab.x.

Kanerva A, Kommonen B, Grönblad M, Tolonen J, Habtemariam A, Virri J, Karaharju E (1997) Inflammatory cells in experimental intervertebral disc injury. Spine (Phila Pa 1976) 22: 2711-2715.

Kawakubo A, Uchida K, Miyagi M, Nakawaki M, Satoh M, Sekiguchi H, Yokozeki Y, Inoue G, Takaso $M$ (2020) Investigation of resident and recruited macrophages following disc injury in mice. J Orthop Res 38: 1703-1709.

Khatab S, van Osch GJ, Kops N, BastiaansenJenniskens YM, Bos PK, Verhaar JA, Bernsen MR, van Buul GM (2018) Mesenchymal stem cell secretome reduces pain and prevents cartilage damage in a murine osteoarthritis model. Eur Cell Mater 36: 218230.

Krock E, Rosenzweig DH, Currie JB, Bisson DG, Ouellet JA, Haglund L (2017) Toll-like receptor activation induces degeneration of human intervertebral discs. Sci Rep 7: 17184. DOI: 10.1038/ s41598-017-17472-1.

Larsson K, Runesson E, Junevik K, Rydevik B, Brisby H (2011) Effects of intervertebral disc cells on neurite outgrowth from dorsal root ganglion explants in culture. Spine (Phila Pa 1976) 36: 600-606. 
Larsson K, Rydevik B, Olmarker K (2005) Disc related cytokines inhibit axonal outgrowth from dorsal root ganglion cells in vitro. Spine (Phila Pa 1976) 30: 621-624.

Le Maitre CL, Hoyland JA, Freemont AJ (2007) Catabolic cytokine expression in degenerate and herniated human intervertebral discs: IL-1beta and TNFalpha expression profile. Arthritis Res Ther 9: R77. DOI: 10.1186/ar2275.

Lee JM, Song JY, Baek M, Jung H-Y, Kang H, Han IB, Kwon YD, Shin DE (2011) Interleukin-1 $\beta$ induces angiogenesis and innervation in human intervertebral disc degeneration. J Orthop Res 29: 265-269.

Li W, Ren G, Huang Y, Su J, Han Y, Li J, Chen X, Cao K, Chen Q, Shou P, Zhang L, Yuan ZR, Roberts AI, Shi S, Le AD, Shi Y (2012) Mesenchymal stem cells: a double-edged sword in regulating immune responses. Cell Death Differ 19: 1505-1513.

Liu X, Krishnamoorthy D, Lin L, Xue P, Zhang F, Chi L, Linhardt RJ, Iatridis JC (2018) A method for characterising human intervertebral disc glycosaminoglycan disaccharides using liquid chromatography-mass spectrometry with multiple reaction monitoring. Eur Cell Mater 35: 117-131.

Mancuso P, Raman S, Glynn A, Barry F, Murphy JM (2019) Mesenchymal stem cell therapy for osteoarthritis: the critical role of the cell secretome. Front Bioeng Biotechnol 7: 9. DOI: 10.3389/ fbioe.2019.00009.

McCann MR, Séguin CA (2016) Notochord cells in intervertebral disc development and degeneration. J Dev Biol 4: 3. DOI: 10.3390/jdb4010003.

Miguelez-Rivera L, Perez-Castrillo S, GonzalezFernandez ML, Prieto-Fernandez JG, Lopez-Gonzalez ME, Garcia-Cosamalon J, Villar-Suarez V (2018) Immunomodulation of mesenchymal stem cells in discogenic pain. Spine J 18: 330-342.

Millward-Sadler SJ, Costello PW, Freemont AJ, Hoyland JA (2009) Regulation of catabolic gene expression in normal and degenerate human intervertebral disc cells: implications for the pathogenesis of intervertebral disc degeneration. Arthritis Res Ther 11: R65. DOI: 10.1186/ar2693.

Miyamoto T, Muneta T, Tabuchi T, Matsumoto K, Saito H, Tsuji K, Sekiya I (2010) Intradiscal transplantation of synovial mesenchymal stem cells prevents intervertebral disc degeneration through suppression of matrix metalloproteinase-related genes in nucleus pulposus cells in rabbits. Arthritis Res Ther 12: R206. DOI: 10.1186/ar3182.

Miyazaki T, Kobayashi S, Takeno K, Meir A, Urban J, Baba H (2009) A phenotypic comparison of proteoglycan production of intervertebral disc cells isolated from rats, rabbits, and bovine tails; which animal model is most suitable to study tissue engineering and biological repair of human disc disorders? Tissue Eng Part A 15: 3835-3846.

Nakazawa KR, Walter BA, Laudier DM, Krishnamoorthy D, Mosley GE, Spiller KL, Iatridis JC (2018) Accumulation and localization of macrophage phenotypes with human intervertebral disc degeneration. Spine J 18: 343-356.

Nap RJ, Szleifer I (2008) Structure and interactions of aggrecans: statistical thermodynamic approach. Biophys J 95: 4570-4583.

Neto E, Alves CJ, Leitão L, Sousa DM, Alencastre IS, Conceição F, Lamghari M (2017) Axonal outgrowth, neuropeptides expression and receptors tyrosine kinase phosphorylation in 3D organotypic cultures of adult dorsal root ganglia. PLoS One 12: e0181612. DOI: 10.1371/journal.pone.0181612.

Neto E, Sousa DM, Conceição F, Leitão L, Alves CJ, Alencastre IS, West J, Oreffo ROC, Lamghari M (2018) Osteoclasts control sensory neurons axonal growth through epidermal growth factor receptor signaling. bioRxiv: 259218. DOI: $10.1101 / 259218$. This article is a preprint and has not been certified by peer review.

O'Connell GD, Vresilovic EJ, Elliott DM (2007) Comparison of animals used in disc research to human lumbar disc geometry. Spine (Phila Pa 1976) 32: 328-333.

Orozco L, Soler R, Morera C, Alberca M, Sánchez A, García-Sancho J (2011) Intervertebral disc repair by autologous mesenchymal bone marrow cells: a pilot study. Transplantation 92: 822-828.

Pratta MA, Yao W, Decicco C, Tortorella MD, Liu RQ, Copeland RA, Magolda R, Newton RC, Trzaskos JM, Arner EC (2003) Aggrecan protects cartilage collagen from proteolytic cleavage. J Biol Chem 278: 45539-45545.

Qi L, Wang R, Shi Q, Yuan M, Jin M, Li D (2019) Umbilical cord mesenchymal stem cell conditioned medium restored the expression of collagen II and aggrecan in nucleus pulposus mesenchymal stem cells exposed to high glucose. J Bone Miner Metab 37: 455-466.

Quero L, Klawitter M, Schmaus A, Rothley M, Sleeman J, Tiaden AN, Klasen J, Boos N, Hottiger MO, Wuertz K, Richards PJ (2013) Hyaluronic acid fragments enhance the inflammatory and catabolic response in human intervertebral disc cells through modulation of toll-like receptor 2 signalling pathways. Arthritis Res Ther 15: R94. DOI: 10.1186/ ar4274.

Raj PP (2008) Intervertebral disc: anatomyphysiology-pathophysiology-treatment. Pain Pract 8: $18-44$.

Rannou F, Corvol M, Revel M, Poiraudeau S (2001) Disk degeneration and disk herniation: the contribution of mechanical stress. Joint Bone Spine 68: 543-546.

Risbud MV, Shapiro IM (2014) Role of cytokines in intervertebral disc degeneration: pain and disc content. Nat Rev Rheumatol 10: 44-56.

Rosell A, Arai K, Lok J, He T, Guo S, Navarro M, Montaner J, Katusic ZS, Lo EH (2009) Interleukin$1 \beta$ augments angiogenic responses of murine endothelial progenitor cells in vitro. J Cereb Blood Flow Metab 29: 933-943.

Rustenburg CME, Emanuel KS, Peeters M, Lems WF, Vergroesen P-PA, Smit TH (2018) Osteoarthritis 
and intervertebral disc degeneration: quite different, quite similar. JOR Spine 1: e1033. DOI: 10.1002/ jsp2.1033.

Sakai D, Mochida J, Yamamoto Y, Nomura T, Okuma M, Nishimura K, Nakai T, Ando K, Hotta T (2003) Transplantation of mesenchymal stem cells embedded in Atelocollagen ${ }^{\circledR}$ gel to the intervertebral disc: a potential therapeutic model for disc degeneration. Biomaterials 24: 3531-3541.

Sakai D, Schol J (2017) Cell therapy for intervertebral disc repair: clinical perspective. J Orthop Translat 9: 8-18.

Salgado AJ, Sousa JC, Costa BM, Pires AO, Mateus-Pinheiro A, Teixeira FG, Pinto L, Sousa N (2015) Mesenchymal stem cells secretome as a modulator of the neurogenic niche: basic insights and therapeutic opportunities. Front Cell Neurosci 9: 249-249.

Séguin CA, Pilliar RM, Roughley PJ, Kandel RA (2005) Tumor necrosis factor-alpha modulates matrix production and catabolism in nucleus pulposus tissue. Spine (Phila Pa 1976) 30: 1940-1948.

Shamji MF, Setton LA, Jarvis W, So S, Chen J, Jing L, Bullock R, Isaacs RE, Brown C, Richardson WJ (2010) Proinflammatory cytokine expression profile in degenerated and herniated human intervertebral disc tissues. Arthritis Rheum 62: 1974-1982.

Silva AJ, Ferreira JR, Cunha C, Corte-Real JV, BessaGonçalves M, Barbosa MA, Santos SG, Gonçalves RM (2019) Macrophages down-regulate gene expression of intervertebral disc degenerative markers under a pro-inflammatory microenvironment. Front Immunol 10: 1508-1508.

Silva AM, Almeida MI, Teixeira JH, Maia AF, Calin GA, Barbosa MA, Santos SG (2017) Dendritic cellderived extracellular vesicles mediate mesenchymal stem/stromal cell recruitment. Sci Rep 7: 1667. DOI: 10.1038/s41598-017-01809-x.

Sitte I, Kathrein A, Klosterhuber M, Lindtner RA, Neururer SB, Rauch S, Kuhn V, Schmoelz W (2014) Morphological similarities after compression trauma of bovine and human intervertebral discs: do disc cells have a chance of surviving? J Orthop Res 32: 1198-1207.

Tao H, Han Z, Han ZC, Li Z (2016) Proangiogenic features of mesenchymal stem cells and their therapeutic applications. Stem Cells Int 2016: 1314709-1314709.

Teixeira GQ, Boldt A, Nagl I, Pereira CL, Benz K, Wilke HJ, Ignatius A, Barbosa MA, Goncalves RM, Neidlinger-Wilke C (2016) A degenerative/ proinflammatory intervertebral disc organ culture: an ex vivo model for anti-inflammatory drug and cell therapy. Tissue Eng Part C Methods 22: 8-19.

Teixeira GQ, Pereira CL, Ferreira JR, Maia AF, Gomez-Lazaro M, Barbosa MA, Neidlinger-Wilke C, Goncalves RM (2018) Immunomodulation of human mesenchymal stem/stromal cells in intervertebral disc degeneration: insights from a proinflammatory/ degenerative ex vivo model. Spine (Phila Pa 1976) 43: E673-E682.
Vynios DH (2014) Metabolism of cartilage proteoglycans in health and disease. Biomed Res Int 2014: 452315. DOI: 10.1155/2014/452315.

Wang M, Yuan Q, Xie L (2018) Mesenchymal stem cell-based immunomodulation: properties and clinical application. Stem Cells Int 2018: 3057624 . DOI: 10.1155/2018/3057624.

Wang S, Wei J, Fan Y, Ding H, Tian H, Zhou X, Cheng L (2018) Progranulin is positively associated with intervertebral disc degeneration by interaction with IL-10 and IL-17 through TNF pathways. Inflammation 41: 1852-1863.

Wei A, Shen B, Williams L, Diwan A (2014) Mesenchymal stem cells: potential application in intervertebral disc regeneration. Transl Pediatr 3: 71-90.

Xue J, Wang J, Liu Q, Luo A (2013) Tumor necrosis factor- $\alpha$ induces ADAMTS-4 expression in human osteoarthritis chondrocytes. Mol Med Rep 8: 17551760.

Yoshikawa T, Ueda Y, Miyazaki K, Koizumi M, Takakura Y (2010) Disc regeneration therapy using marrow mesenchymal cell transplantation: a report of two case studies. Spine (Phila Pa 1976) 35: E475-E480.

Zeng $\mathrm{X}$, Lin J, Wu H, Yu J, Tu M, Cheang LH, Zhang J (2020) Effect of conditioned medium from human umbilical cord-derived mesenchymal stromal cells on rejuvenation of nucleus pulposus derived stem/progenitor cells from degenerated intervertebral disc. Int J Stem Cells 13: 257-267.

\section{Discussion with Reviewers}

Amir Kamali: How would you anticipate MSCsec to be administered clinically?

Authors: We envisage an intradiscal administration of MSCsec. MSCsec could be administered solubilised in a vehicle (e.g. saline solution) or incorporated in a delivery system to achieve a sustained release. However, since disc local injection could possibly injure either the annulus fibrosus or the endplate, needle size would be crucial. A biomaterial-based delivery system for MSCsec would be advantageous if it were possible to seal the lesion while offering biomechanical stability to the disc tissue. Hydrogels with similar biomechanical characteristics to IVD tissue have been previously developed (Liang et al., 2019, additional reference; Shoma Suresh et al., 2020, additional reference; Waters et al., 2018, additional reference) and could be tested.

Amir Kamali: What further experiments do you suggest for investigating the role of MSCsec in a loaded disc culture system?

Authors: The role of MSCsec should be tested in more physiological model of IVD degeneration, before moving to pre-clinical/clinical tests. Although interesting, the ex vivo model used has limitations, as discussed previously (Teixeira et al., 2016). Therefore, it would be interesting to study 
this immunomodulatory role of MSCsec under mechanical loaded conditions, using bioreactors, to induce cycles of dynamic loading. It would also be interesting to compare different types of loading such as compression, tension, etc. in synergy with pro-inflammatory stimuli, as previously performed on the AF (Saggese et al., 2019, additional reference).

Reviewer II: As the MSCsec is rich in a number of inflammatory cytokines, please discuss the influence of injecting this into a disc in vivo, on potential chemotaxis and immune cell activation. Where upon rupture of the AF (due to needle insertion) the disc is now exposed to the immune system?

Authors: The MSCs secretome has been repetitively reported to have a strong immunomodulatory potential in many scenarios (Ferreira et al., 2018). Its ability to induce macrophage polarisation from a proinflammatory phenotype (M1) to a pro-regenerative phenotype (M2) has also been described (Vasandan et al., 2016, additional reference; Wang et al., 2020, additional reference; Zhao et al., 2019, additional reference). Thus, and considering the multiple reports showing macrophages as the main immune cell found in injured/degenerated IVDs (Koike et al., 2003, additional reference; Nakazawa et al., 2018; Rothoerl et al., 1998, additional reference), it could be expected that the presence of the MSCsec during such exposure would influence positively the inflammatory cascade at the site of injury.

\section{Additional References}

Koike Y, Uzuki M, Kokubun S, Sawai T (2003) Angiogenesis and inflammatory cell infiltration in lumbar disc herniation. Spine (Phila Pa 1976) 28: 1928-1933.

Liang M, Liu W, Peng Z, Lv S, Guan Y, An G, Zhang Y, Huang T, Wang Y (2019) The therapeutic effect of secretome from human umbilical cordderived mesenchymal stem cells in age-related osteoporosis. Artif Cells Nanomed Biotechnol 47: 1357-1366.
Rothoerl R, Woertgen C, Holzschuh M, Brehme K, Rüschoff J, Brawanski A (1998) Macrophage tissue infiltration, clinical symptoms, and signs in patients with lumbar disc herniation. A clinicopathological study on 179 patients. Acta Neurochir (Wien) 140: 1245-1248.

Shoma Suresh K, Bhat S, Guru BR, Muttigi MS, Seetharam RN (2020) A nanocomposite hydrogel delivery system for mesenchymal stromal cell secretome. Stem Cell Res Ther 11: 205. DOI: 10.1186/ s13287-020-01712-9.

Saggese T, Teixeira GQ, Wade K, Moll L, Ignatius A, Wilke HJ, Goncalves RM, Neidlinger-Wilke C (2019) Georg Schmorl prize of the German Spine Society (DWG) 2018: combined inflammatory and mechanical stress weakens the annulus fibrosus: evidences from a loaded bovine AF organ culture. Eur Spine J 28: 922-933.

Vasandan AB, Jahnavi S, Shashank C, Prasad P, Kumar A, Prasanna SJ (2016) Human mesenchymal stem cells program macrophage plasticity by altering their metabolic status via a PGE(2)-dependent mechanism. Sci Rep 6: 38308. DOI: 10.1038/srep38308.

Wang J, Xia J, Huang R, Hu Y, Fan J, Shu Q, Xu J (2020) Mesenchymal stem cell-derived extracellular vesicles alter disease outcomes via endorsement of macrophage polarization. Stem Cell Res Ther 11: 424. DOI: 10.1186/s13287-020-01937-8.

Waters R, Alam P, Pacelli S, Chakravarti AR, Ahmed RPH, Paul A (2018) Stem cell-inspired secretome-rich injectable hydrogel to repair injured cardiac tissue. Acta Biomater 69: 95-106.

Zhao J, Li X, Hu J, Chen F, Qiao S, Sun X, Gao L, Xie J, Xu B (2019) Mesenchymal stromal cellderived exosomes attenuate myocardial ischaemiareperfusion injury through miR-182-regulated macrophage polarization. Cardiovasc Res 115: 12051216.

Editor's note: The Scientific Editor responsible for this paper was Sibylle Grad. 